\title{
Can Online Wait Be Managed? The Effect of FILLER INTERFACES AND PRESENTATION MODES On Perceived Waiting TIME ONLINE ${ }^{1}$
}

\author{
Younghwa Lee \\ Department of Management, College of Business Administration, University of Northern lowa, \\ Cedar Falls, IA 50614 U.S.A. \{gabe.lee@uni.edu\}
}

Andrew N. K. Chen

Accounting and Information Systems, School of Business, University of Kansas, 1300 Sunnyside Avenue, Lawrence, KS 66045 U.S.A. \{achen@ku.edu\}

Virginia Ilie

School of Management, California Luthern University, 60 West Olsen Road, Thousand Oaks, CA 91360 U.S.A. \{ilie.virginia@gmail.com\}

\begin{abstract}
Long waits online undermine users' evaluations of Web sites and their providers, triggering abandonment behaviors. Yet e-business researchers and practitioners have not perfected mechanisms to respond to online wait issues. A filler interface that runs during the wait for search results may influence online users' perceived waiting time (PWT); however, no scientific investigation has attempted to design effective filler interfaces for managing online waits. By adopting resource allocation theory, cognitive absorption theory, and human computer interaction (HCI) theories (competition for attention, visual search, and motion effect), we design diverse filler interfaces and investigate their effects on antecedents of PWT. The proposed research model considers cognitive absorption factors such as temporal dissociation, focused immersion, and heightened enjoyment as antecedents of PWT, which in turn triggers three outcomes: affective appraisals, cognitive appraisals, and Web site use intention. A multistage, multimethod approach is used to test the research hypotheses. In the first stage, we compare a filler interface condition with a no-filler interface condition, and find the superiority of a filler interface with respect to inducing focused immersion and temporal dissociation. In the second stage, we conduct two controlled experiments to examine whether filler interfaces with various designs (varying the presence and relevance of image, text, and image motion) distinctly influence antecedents of PWT and confirm their distinctive effects on focused immersion, temporal dissociation, and heightened enjoyment. In addition, by conducting a structural equation modeling analysis, we find that our research model explains 51 percent, 51 percent, 44 percent, and 45 percent of the variance in PWT, affective appraisals, cognitive appraisals, and Web site use intention respectively. Theoretical and practical implications of these findings are provided.
\end{abstract}

Keywords: Filler interface, interface design, online wait management, perceived waiting time, cognitive absorption, motion effect, competition for attention, visual search, resource allocation

\footnotetext{
${ }^{1}$ Henri Barki was the accepting senior editor for this paper. Hock Chuan Chan served as the associate editor.

The appendices for this paper are located in the "Online Supplements" section of the MIS Quarterly's website (http://www.misq.org).
} 


\section{Introduction}

Customers not only demand quality, they also demand speed. They do not tolerate waiting in line for long periods of time.

Katz et al. 1991, p. 44

Waiting, a pervasive and inseparable component of people's shopping or service-getting experience, negatively affects their overall satisfaction with products, services, and stores (Rajala and Hantula 2000; Tom and Lucey 1997; Weinberg 2000). Studies in brick-and-mortar businesses confirm that long waiting times create stress and dissatisfaction among customers (Pruyn and Smidts 1998). Researchers, therefore, proposed various fillers such as music, news bulletins, and magazines, which were shown to significantly reduce perceived waiting time (PWT) (Antonides et al. 2002; Dellaert and Kahn 1999; Katz et al. 1991).

Waiting also occurs online although online waiting differs from traditional waiting in that (1) people have much shorter time expectations and are more impatient online, (2) online visitors' PWT can be manipulated with Web site design components, and (3) the impact of waiting on evaluations of services or merchants may be greater online than in brick-andmortar environments. A recent study reports that the maximum tolerable waiting time online is only two seconds (Nah 2004). Long waiting times may be the single greatest problem for e-business, resulting in online customer frustration and negative attitudes, which in turn may cause purchase abandonment and customer switching behavior (Dennis and Taylor 2006; Galletta et al. 2004; Rajala and Hantula 2000; Rose et al. 2005).

Most studies in the Information Systems domain tackle issues of actual waiting and response time by focusing on technological solutions (e.g., Shneiderman and Plaisant 2010). While this approach has its contributions by focusing on the "attributable delay" (Rose and Straub 2001; Rose et al. 2005), companies can only invest so much in advanced systems, servers, databases, and networks (Rose et al. 2005). Thus, the online wait problem may not be solved by only using technical solutions (Ryan and Valverde 2006). Under these circumstances, it becomes crucial for e-businesses to minimize not only the objective or actual waiting time but also their customers' perceived waiting time (Dube-Rioux et al. 1989; Katz et al. 1991).

Results from previous research also seem to support the importance of considering not only objective (measured) time, but also the perceived dimension of the wait. For instance, Barnett and Saponaro (1985) and Hornik (1984) suggested that the length of the wait can be more appropriately measured by PWT than by objective waiting time. Other authors showed that PWT may be more important than objective time in determining customer experience, evaluation, and behavior (Barnett and Saponaro 1985; Davis and Vollmann 1990; Taylor 1994; Tom and Lucey 1997). In addition, Thompson et al. (1996) noted that shorter PWT was associated with a positive overall satisfaction while actual waiting time was not. Tom and Lucey (1997) also found that customer satisfaction was determined by PWT rather than the objective time. Finally, a study by Rose et al. (2005) revealed that the objective download delay was not a critical determinant of the attitude toward an e-retailer.

Thus, we choose to focus on PWT (rather than objective time) as the construct of interest in an online wait environment. A potential means to reduce PWT online involves a filler interface (Gorn et al. 2004), which is an interface that users see while they wait for search results or expected outputs. A filler interface can include diverse Web design components such as images, text, progress bar, background color, or multimedia, and is pervasively used in e-business environments, especially online travel sites. However, there is currently no scientific investigation into the effectiveness of such filler interfaces in managing time perceptions online or their design characteristics. Therefore, this study tackles the following research questions:

(1) Can a filler interface be used to influence PWT in an online environment?

(2) If so, what design characteristics of a filler interface can be used in order to effectively manipulate users' perceptions of online wait and foster positive evaluations of the Web site?

With this objective, we first build a research model by integrating multiple theories: resource allocation (Zakay 1989; Zakay and Hornik 1991), cognitive absorption (Agarwal and Karahanna 2000), and human-computer interaction (HCI) theories, namely competition for attention (Janiszewski 1998), visual search (Bacon and Egeth 1994; Folk et al. 1992; Yantis and Egeth 1999), and motion effect (Ball and Tronick 1971; Barten et al. 1971; Detenber et al. 1998; Simons et al. 2000; Simons et al. 1999). Second, using these theoretical lenses, we propose that when users see a well-designed filler interface, they can reach a state of deep involvement with the interface (called cognitive absorption) which directly impacts their PWT. We develop hypotheses for investigating the effects of the presence and various designs of filler interfaces on cognitive absorption factors such as focused immersion, temporal dissociation, and heightened enjoyment. We then 
examine the nomological network of these constructs, PWT, and overall evaluations of a Web site. In order to test the proposed hypotheses and validate our research model, we develop a simulated online travel site with diverse filler interfaces in three controlled experiments. Texts and images are used as design components, which we manipulate with regard to their presence, level of relevance, and image motion. Results from three controlled experiments as well as the structural equation model analysis are presented and elaborated. Finally, we discuss theoretical contributions, practical implications, and future research directions from our findings.

\section{Theoretical Background}

We build our study around three theoretical bases: resource allocation theory, cognitive absorption theory, and three $\mathrm{HCI}$ theories, namely competition for attention theory, visual search theory, and motion effect theory. We describe each theory in detail in the following sections.

\section{Resource Allocation Theory}

Resource allocation theory (Kahneman 1973; Zakay 1989) is rooted in a view where there is a limited pool of processing resources (i.e., attention, capacity, or cognitive effort) possessed by humans (Hirst and Kalmar 1987; Kahneman 1973; McNeil et al. 1991; Navon and Gopher 1979). The premise of the theory is that individuals are naturally occupied with the passage of time and actively engage in time estimation during the entire waiting period. In other words, people perceive longer wait duration if they pay more attention to the wait and their time is not "filled" (Maister 1985). Meanwhile, if nontemporal objects (or stimuli) are introduced during the wait, people allocate a certain amount of resources to processing and reacting to the stimuli, which results in reduced resource allocation for time estimation (Zakay 1989). That is, if more nontemporal information processing (distracter or stimulus) is required, a person allocates fewer resources (attention) to the temporal information and vice versa.

Researchers (e.g., Taylor 1994) actively applied this theory for predicting customers' estimation of wait (delay) duration. They noted that providing individuals with feedback or various stimuli by filling the waiting time can distract their attention from the passage of time and the duration of an event (Baker and Cameron 1996; Gorn et al. 2004; Zviran et al. 2006). This is because provision of such stimuli leads individuals to allocate more cognitive resources for processing the stimuli-related information rather than actual time estimation (Zakay and Hornik 1991). Hence, less attention is paid to the wait itself, which results in shorter time estimates. Several studies validated this theory in various contexts such as telephone waiting and delayed flights (Antonides et al. 2002; Dellaert and Kahn 1999; Katz et al. 1991; Taylor 1994), and download delay on the Internet (Rose et al. 2005).

\section{Cognitive Absorption Theory}

A rather new theoretical perspective that explains online users' holistic experiences with using new technologies is cognitive absorption theory (Agarwal and Karahanna 2000). Cognitive absorption theory is rooted in psychological theories that conceptualize absorption as a trait (Tellegen 1982), theory of flow (Csikszentmihalyi 1990), and cognitive engagement theory (Webster and Ho 1997). Agarwal and Karahanna (2000) integrated these theoretical bases and further explored the realm of cognitive absorption in an online environment. As opposed to past conceptualizations of absorption as a trait, Agarwal and Karahanna (2000) view cognitive absorption as a state which captures the essence of an individual's subjective experiences and which can be an outcome of a particular configuration of individual and situational factors (p. 668). In their view, cognitive absorption is "a state of deep involvement with software" (p. 665). Cognitive absorption captures the totality of an individual's experience with new technologies and is likely to be achieved with hedonic technologies that are "visually rich and appealing" (Agarwal and Karahanna 2000, p. 688), which is the case of many Web interfaces.

Cognitive absorption in an online environment encompasses five dimensions (Agarwal and Karahanna 2000): (1) temporal dissociation, (2) focused attention, (3) heightened enjoyment, (4) control, and (5) curiosity. Temporal dissociation refers to an individual's inability to register the passage of time while engaged in an activity. Focused immersion represents an experience of total engagement, where other attentional demands are rather ignored. Heightened enjoyment captures the pleasurable aspects of the interaction while control represents a user's perception of being in charge of the interaction. Finally, curiosity refers to the extent to which the experience arouses an individual's sensory and cognitive curiosity.

Previous research shows that cognitive absorption successfully predicts individuals' IT acceptance behaviors. For example, cognitive absorption was found to have positive associations with perceived usefulness and perceived ease-ofuse while using the World Wide Web (Agarwal and Karahanna 2000). Saade and Bahli (2005) defined cognitive 
absorption as time distortion, focused immersion, and heightened enjoyment, and noted its positive influence on perceived usefulness and ease-of-use on Internet-based learning systems. In a virtual team environment, Rutkowski et al. (2007) found that teams with focused immersion and time distortion showed high performance. Finally, Roca et al. (2006) identified a significant influence of cognitive absorption on e-learning service satisfaction.

While several studies used the construct of cognitive absorption to investigate outcomes such as acceptance and performance, few studies looked at the actual formation of cognitive absorption perceptions. In fact, Agarwal and Karahanna strongly advised researchers to further their inquiry into the nomological net of cognitive absorption in order to identify other predictors of cognitive absorption (p. 687). They also suggested more research focus on measuring cognitive absorption during usability testing of Web sites in lab settings (p. 689). In this study, we center our inquiry on the first three dimensions of cognitive absorption theory since the latter two dimensions do not correspond to our proposed model. ${ }^{2}$

\section{$\mathrm{HCl}$ Theories: Competition for Attention, Visual Search, and Motion Effect}

Researchers in the HCI domain have a long history of investigating designs of usable interfaces (Morrison and Vogel 1998), Web sites (Nielsen 2000), and virtual worlds (Lee et al. 2009). This study refers to three relevant HCI theoriesnamely, competition for attention, visual search, and motion effect - to provide the theoretical foundation for the design of various filler interfaces and hypotheses formulation in our study. These theories are based on the notion that individuals have a limited amount of attention and information processing capabilities available (Kahneman 1973) and they selectively process information by responding to various stimuli in their visual field (Van der Heijden 1992). Attention, however, can be influenced by provision of various stimuli. As a response to stimuli, individuals develop an "orienting response" (Ohman 1977) that holds attention if the stimuli are different from others (Janiszewski 1998), relevant to the task (Yantis and Egeth 1999), or moving (Nielsen 2000). Each of the theories we discuss below provides us with a basis for understanding the various stimuli that may capture and hold users'

\footnotetext{
${ }^{2}$ We did not include perceived uncertainty and control because they were not appropriate for this study context where (1) wait duration is very short; (2) wait duration information is not provided; and (3) participants of controlled experiments inherently expect to see search results instead of being concerned about not seeing the search results.
}

attention when placed on filler interfaces, thus influencing waiting time perceptions.

Competition for attention theory (Janiszewski 1998) states that focal and non-focal objects compete for attention within an individual's visual field. When an object is the focus of attention, other objects will constantly compete for attention with the focal object. This theory is rooted in the physiology of the human visual system with emphasis on where visual receptors are located on the retina and how they process information from a focus area. Thus, humans' visual system recognizes differences in the intensity of signals generated by objects located within their visual field (Janiszewski 1998; Steinman and Levinson 1990). Because human attention span is limited (Woodside and Clokey 1974), more attentiongetting objects would determine focused attention (Hong et al. 2005; Janiszewski 1998). Salience and distance of an object from the visual field determine the amount of attention an object receives. As objects are located further away from the visual point of focus, they become harder to see and therefore less likely to compete for attention. Increased salience of the visual object (e.g., contrast, size, layout, and content), however, maximizes the likelihood an object will be selected for viewing (Janiszewski 1998).

A salient visual object is one that can be efficiently detected in visual search (Yantis and Egeth 1999). Hence salience can be granted by any feature or stimulus that is perceived as locally unique in the visual field (Yantis and Egeth 1999). Color, size, orientation, and motion are examples of such stimuli. For example, researchers in experimental psychology (e.g., Yantis and Jonides 1984) found evidence that a target with distinct characteristics captured more attention and detection faster when the target was distinct from others (e.g., a sudden-onset). Todd and Kramer (1994) also found that uniquely colored or luminous letters can capture more attention in a search task.

In sum, competition for attention theory suggests that by manipulating various stimuli, a visual object can receive more attention than others. It also suggests that attention is captured solely by the properties of the stimulus, even if the stimulus is irrelevant to the task at hand. This theory can be applied in a Web environment in order to understand how visual design stimuli on a filler interface may shift individuals' attention to a focal point on the interface targeted by the stimuli. Only a few researchers applied this theory in IS (Hong et al. 2005; Jiang and Benbasat 2007) and found a significant effect of visual presentation formats in interface design on performance measures (information search time and recall) as well as attitudes toward the Web site. Jiang and 
Benbasat (2007) also found significant influence of salient presentation modes of the products on perceived diagnosticity and focused attention. They found that the more interactive and vivid the images of products, the more favorable the attitudes toward the Web site and its products.

Visual search theory (Bacon and Egeth 1994; Folk et al. 1992; Yantis and Egeth 1999) challenges the view that attention is directed in a pure stimulus-driven fashion. Various authors in experimental psychology distinguish between stimulus-driven attentional guidance and goal-directed attentional guidance (Bacon and Egeth 1992; Hillstrom and Yantis 1994). Stimulus-driven attentional guidance occurs when attention is drawn to a stimulus that is task-irrelevant. On the other hand, goal-directed attentional guidance occurs when individuals shift their attention to an object in their visual field based on task characteristics. Visual search theory postulates that individuals selectively allocate their attention into processing information in their visual field (e.g., user interfaces) based not only on the salience of the objects presented to them but most importantly on their perceived relevance to a search task. Specifically, visual search theorists note that object salience alone (e.g., contrast, color, size, movement) is not sufficient in drawing users' attention. The object of attention also needs to be perceived as relevant to the search task. In other words, individuals may ignore visually salient objects on Web sites if they perceive them to be irrelevant to their tasks.

Various researchers in experimental psychology support this claim. For instance, Yantis and Egeth (1999) found that in visual search, search efficiency increased with the degree of useful information provided about the stimulus as well as its visual salience. Folk et al. (1992) argued that attention shifts can never completely be stimulus-driven because they are modulated by an individual's attentional control setting which is a "function of current behavioral goals" (p. 1041). They suggested that shifts of attention are critically dependent on the relationship between the stimulus properties and task demands (p. 1030). Very few researchers in IS used this theory to investigate online user behaviors (Hong et al. 2005). In the context of our study, this theory provides important insights into including task-relevant text and images on filler interfaces and investigating their impact on waiting time perceptions.

Motion effect theory is grounded in neurological science and biological mechanisms of human information processing. Motion constitutes a fundamental aspect of the physical world and the human brain has specialized nerve cells that detect and process motion (Anstis et al. 1998; Goldstein 1989;
Spilman 1999). Motion detection is a biological enduring disposition (Hong et al. 2007), which is the direct result of humans' innate predisposition for moving objects (Ball and Tronick 1971; Barten et al. 1971). In essence, this theory predicts that as compared to static images, moving images capture more attentional and emotional resources (Detenber et al. 1998; Diao and Sundar 2004; Fasolo et al. 2006; Hong et al. 2007; Simons et al. 2000; Simon et al. 1999) because motion continuously presents individuals with new information. Moving images have also an overwhelming effect on human peripheral vision (Girelli and Luck 1997). Hence a stimulus that moves within the peripheral vision attracts attention quickly (Nielsen 2000) because the stimulus disturbs the systems' equilibrium (Goldstein 1989). As a result, there is a sudden attention shift or "orienting response" (Lang 1990) including an eye fixation on the locus of change (Goldstein 1989). The "oriented response" caused by moving images can take two forms: (1) more focused user attention on the moving object (Diao and Sundar 2004; Fasolo et al. 2006; Hong et al. 2005, 2007) and (2) emotional responses including both self-reported arousal (or excitement) and physiological emotions as measured by a sudden deceleration of heart rate or an increase in skin conductance (Detenber et al. 1998; Ravaja 2004; Simons et al. 2000; Simon et al. 1999).

Researchers in marketing and Web advertising have adopted this theory in the context of moving (or animated) images on Web interfaces. For instance, Diao and Sundar (2004) found that stimuli such as pop-up ads elicited orienting responses more than static ads. They concluded that people are apt to orient automatically toward mediated objects that are novel in the immediate visual domain (p. 556). Phillips and Lee (2005) investigated the effect of using animated spokes-characters (animated beings or objects used to promote a product or service) in Internet advertising and found that animation increased character liking and perceived entertainment, and fostered positive attitudes toward the Web site. Other authors in marketing showed that displaying a product in an animated format favored its choice over a product presented in a static format (e.g., Fasolo et al. 2006). In addition, researchers in communication and mass-media showed that messages delivered by a moving-face newscaster were associated with greater emotional arousal than the ones delivered statically (Ravaja 2004).

A few researchers in IS have investigated the effects of moving images (or animation) in information search and browsing activities (Hong et al. 2005, 2007; Lai et al. 2009). In these studies, moving images were conceptualized as banner ad animations (Bayles 2002; Burke et al. 2005), nonbanner ad animations on Web pages (Hong et al. 2007), and 
flash (Hong et al. 2005; Lai et al. 2009). Generally, these studies found that animation attracted Web users' attention (Hong et al. 2007).

\section{Hypotheses Development, Research Methodology, and Results}

The theories presented earlier provide us with a firm foundation for exploring alternative filler interface designs and evaluating their effectiveness on PWT during online waits. However, because of scarcity of past empirical studies in the areas of filler interfaces and online time perceptions, we decided to adopt a more conservative, two-step approach to build and validate our main research hypotheses. As a first step in this direction, we conducted an initial exploratory study (Study 1) to establish whether the presence of a filler interface significantly affects online users' cognitive absorption perceptions, particularly focused immersion and temporal dissociation. Secondly, given significant findings from Study 1 (strong and significant filler interface presence effect), we designed two subsequent experimental studies (Study 2 and Study 3 ) to test finer grained hypotheses regarding alternate designs in filler interfaces and their impacts on users' cognitive time perceptions online. Finally, we conducted a nomological network analysis in order to examine hypotheses related to the effects of filler interfaces on cognitive absorption dimensions, perceived waiting time online, attitudes, and Web site use intention. The hypotheses, research design, and results of each study are described in the next sections. Table 1 provides a summary for the designs of each of the three experimental studies.

\section{First Stage: Validate the Presence Effect of a Filler Interface}

\section{Study 1: Research Hypotheses}

Before we explore the various design characteristics of filler interfaces, we seek to investigate whether the presence of the filler interface itself has an impact on cognitive absorption dimensions such as focused immersion and temporal dissociation.

Focused immersion is an experience of total engagement where other attentional demands are essentially ignored (Agarwal and Karahanna 2000) and a person gives full attention to the task in which he is involved (Shin 2006). This state of immersion in an activity is sometimes referred to as "focused attention" (Shin 2006). Generally, during waits, time is perceived as passing more slowly (Block 1990) if an individual's attention is focused primarily on time rather than anything else (e.g., other stimuli). Competition for attention theory supports the assertion that various stimuli (e.g., a filler interface) can focus online users' attention (Janiszewski 1998). Based on this theory, provision of a filler interface during online waits will focus users' attention such that the filler interface receives more attention than other competing objects in the visual environment. This claim was also supported in online e-business contexts (Hong et al. 2005). Hence, we propose that in online wait contexts, the presence of a filler interface equipped with various visual cues will shift users' attention away from the wait itself and create a feeling of focused immersion in the interaction with the filler. Thus, we propose the following:

\section{H1a: Web sites with filler interfaces will create more focused immersion than Web sites without filler interfaces.}

Temporal dissociation refers to users' inability to register the passage of time while engaged in the interaction with the filler interface (Agarwal and Karahanna 2000). Consistent with resource allocation theory and competition for attention theory, providing individuals with stimuli (e.g., filler interface) during online waits can cause them to concentrate on the interaction with the stimuli and results in their inability to recognize the passage of time (Hui and Tse 1996; Janiszewski 1998; Zakay 1989; Zakay and Hornick 1991). For instance, in a physical service environment, various fillers (e.g., room decorations, background music, magazines, TV, or video) were found to distract individuals' attention from passage of time (Antonides et al. 2002; Dellaert and Kahn 1999; Katz et al. 1991). In addition, competition for attention theory implies that provision of a filler interface as a focal stimulus during online waits may shift individuals' attention toward the filler stimulus. Thus, in the competition for attention process between the focal filler interface stimulus and other objects in the visual environment, the filler interface tends to gain more attention. Such filler interface stimuli provided to users during online waits can also contribute to the perception that the time interval is "filled" (Maister 1985), thus creating temporal dissociation. In other words, provision of a filler interface can "fill" the time between users entering a search term and waiting for the outcome by attracting their attention to the information presented on the interface which in turn can result in distracted attention from the online wait. Thus, we propose that Web sites with filler interfaces will help create more temporal dissociation from wait than sites without such filler interfaces. This logic is reflected in $\mathrm{H} 1 \mathrm{~b}$ : 


\begin{tabular}{|c|c|c|c|c|}
\hline Experiments & Study 1 & Study 2 & Study 3 & Structural Equation Model \\
\hline Objective & $\begin{array}{l}\text { Examine the presence } \\
\text { effect of a filler } \\
\text { interface }\end{array}$ & $\begin{array}{l}\text { Examine the presence } \\
\text { effect of image and text } \\
\text { in a filler interface }\end{array}$ & $\begin{array}{l}\text { Examine the effect of } \\
\text { the relevance of image } \\
\text { and text, and the image } \\
\text { motion }\end{array}$ & $\begin{array}{l}\text { Examine the nomological } \\
\text { network between the ante- } \\
\text { cedents of PWT, PWT, and } \\
\text { overall Web experience }\end{array}$ \\
\hline Subject & $\begin{array}{l}\text { Business school } \\
\text { students }(n=112)\end{array}$ & $\begin{array}{l}\text { Business school } \\
\text { students }(n=127)\end{array}$ & $\begin{array}{l}\text { Business school } \\
\text { students }(n=228)\end{array}$ & $\begin{array}{l}\text { Business school students } \\
\text { ( } n=355 ; \text { pool the data of } \\
\text { study } 2 \text { and } 3 \text { ) }\end{array}$ \\
\hline $\begin{array}{l}\text { Independent } \\
\text { Variables } \\
\text { (Exogenous) }\end{array}$ & $\begin{array}{l}\text { Presence of a filler } \\
\text { interface }\end{array}$ & $\begin{array}{l}\text { Presence of image } \\
\text { Presence of text }\end{array}$ & $\begin{array}{l}\text { Relevance of image } \\
\text { Relevance of text } \\
\text { Image motion }\end{array}$ & $\mathrm{TD}, \mathrm{FI}, \mathrm{HE}$ \\
\hline $\begin{array}{l}\text { Dependent } \\
\text { Variables } \\
\text { (Endogenous) }\end{array}$ & TD, FI & TD, FI & TD, FI, HE & $\begin{array}{l}\text { PWT } \\
\text { CA, AA, UI }\end{array}$ \\
\hline Method & Controlled Experiment & Controlled Experiment & Controlled Experiment & $\begin{array}{l}\text { Structural Equation Model } \\
\text { Analysis }\end{array}$ \\
\hline
\end{tabular}

TD: Time Dissociation; Fl: Focused Immersion; HE: Heightened Enjoyment; PWT: Perceived Waiting Time; CA: Cognitive Appraisals; AA: Affective Appraisals; UI: Use Intention

\section{H1b: $\quad$ Web sites with filler interfaces will create more temporal dissociation than Web sites without filler interfaces.}

\section{Study 1: Research Method and Procedure}

The goal of Study 1 is to examine the effectiveness of filler interfaces in an online wait context. Specifically, we seek to demonstrate that showing online users a filler interface while waiting for search results leads them to perceive higher focused immersion and temporal dissociation than waiting without seeing a filler interface. To test this thesis, we conducted a controlled experiment in order to examine the effect of the presence of a filler interface. We employed this approach because a well-designed lab experiment using actual controls can lead to a deeper understanding of the fundamental principles of human interaction with computers (Rajala and Hantula 2000; Shneiderman and Plaisant 2010).

We designed a simulated online travel Web site for airline ticket purchases (see sample interfaces in Appendix A). Our online travel site, TravelDepot, mimicked major online travel sites. Except for the no-filler interface condition (which only included an input and an output screen), all experimental conditions included an input screen, a filler interface, and an output screen. All screens were designed with a blue-colored background which was deemed to provide the greatest relaxation in both physical and online environments (Gorn et al. 2004).
The simulated travel site used in this experiment was designed to work as follows. An input screen contained two main drop-down boxes for the departure city (Kansas City) and destination (Las Vegas). In order to control the experimental conditions, only these two cities were included on the site. After entering all inputs including departure and return date and number of passengers, users clicked the "Find Flight" button to start the search process. In all scenarios other than the "no filler" one, a filler interface was shown to users during the 16-second wait duration. ${ }^{3}$ An output screen followed the filler interface which showed users various flight schedules. Each subject selected a flight option by clicking the "Select This Flight" button which in turn triggered a questionnaire.

In order to recruit subjects for this experiment, we distributed fliers and class announcements to business school students at a large public midwestern U.S. university who had at least a one-time online purchase experience through an online travel site. Of the 132 subjects recruited, 15 students did not show up for the experiment, and 5 did not successfully complete the survey, leaving a total of 112 usable responses (response rate $=85 \%)$. The participants' mean age was 20.5 years $(\mathrm{SD}=$ 3.4 years) and 55 percent were females. They had an average

\footnotetext{
${ }^{3}$ For setting the waiting time in our experiments, we randomly created 100 scenarios of travel search with different departing dates, arrival dates, departure places, arrival places, and number of passengers. Next we assessed the average waiting time by entering this search information into four commercial travel search Web sites, which provided an average waiting time of 16.5 seconds $(\mathrm{SD}=5.62)$.
} 
of 6.7 years Internet use experience and 4 times online travel site use experience. The participation was voluntary, although students could earn class participation points and an opportunity to win a sweepstake (small cash prize) in return for their participation.

Each participant arrived at the computer lab at a designated time. Two different TravelDepot Web applications (with and without a filler interface) were installed on 32 PCs in a computer lab. Participants were instructed to complete the input screen (including the departure city, destination, date, time, and number of passengers), wait, and then review the results. The filler interface was designed to include one image (e.g., flight attendant) and one piece of text. The selected image and text were similar to the ones most often used in commercial online travel sites (e.g., "TravelDepot always strives to offer the best price and flight selection for customers like you. Please wait while we are searching for your flights. Thank you very much."). The length of text (approximately 30 words) was determined by averaging the length of text shown in filler interfaces of various commercial sites. In the case of the no-filler interface condition, users waited for the search results while seeing the original Travel Depot input screen. Participants were randomly assigned to a filler interface condition $(\mathrm{n}=57)$ and a no-filler condition $(n=55)$. The total amount of time required to complete the task was no more than 30 minutes.

Out of the five variables introduced in cognitive absorption theory, focused immersion and temporal dissociation were selected as two dependent variables for Study 1. Curiosity, perceived control, and heightened enjoyment were not appropriate for this study because (1) wait duration was very short, (2) wait duration information was not provided, and (3) the filler interfaces contained generic images/text which would not elicit hedonic perceptions.

Based on our literature review, we identified four focused immersion items from Agarwal and Karahanna's (2000) study (see a list of instrument items in Appendix B). In order to ensure content validity, items were pretested with eight experts, consisting of faculty members, doctoral students, and customers using online travel sites. Subsequently, some modifications were made to the wording and format of the instrument.

\section{Study 1: Analysis of Psychometric Properties and Results}

We conducted an exploratory factor analysis in order to (1) determine the psychometric properties of the instrument for focused immersion and temporal dissociation, and
(2) investigate the convergent and discriminant validity and reliability. As shown in Table 2, the items measuring the same construct correlated with one another, and their factor loading scores were all greater than .7, in support of convergent validity. All Eigenvalues of the constructs were greater than $1(\mathrm{FI}=5.01, \mathrm{TD}=2.32)$. Further, all items correlated more closely with other items intended to measure the same factor than with items used to measure a different construct, providing evidence of construct validity. Finally, all constructs exhibited Cronbach's alphas greater than .916, which demonstrate adequate reliability.

A MANOVA test was conducted to examine the effect of the presence of a filler interface on temporal dissociation and focused immersion. We found a significant effect of the presence of a filler interface (Wilks' $\lambda=14.361, \mathrm{p}<.001$ ). This result implies that a Web site with a filler interface performed better than one without such an interface in terms of drawing users' attention while waiting, as well as inducing perceptions that time passed faster. Subsequent ANOVA tests showed that participants in the filler interface condition perceived significantly higher levels of focused immersion $\left(\mathrm{Mean}_{\mathrm{F}}=4.25, \mathrm{Mean}_{\mathrm{NF}}=2.98, \mathrm{~F}=33.04, \mathrm{p}<.001\right)$ and temporal dissociation $\left(\operatorname{Mean}_{\mathrm{F}}=3.91, \operatorname{Mean}_{\mathrm{NF}}=3.01, \mathrm{~F}=\right.$ $18.81, \mathrm{p}<.001$ ) than those in the no-filler interface condition. Thus, H1 was supported. Once the presence effect of a filler interface was established, we proceeded to the second stage and conducted Study 2 and Study 3 to further explore the various designs of filler interfaces and their impact on wait perceptions online.

\section{Second Stage: Validate Effects of Diverse Filler Interface Designs on Time Perceptions}

Encouraged by the significant findings from Study 1 showing a strong presence effect of a filler interface in manipulating cognitive absorption perceptions online, we attempt to investigate further alternate designs of a filler interface and their subsequent impacts. From the theoretical bases presented earlier, we examine diverse filler interface designs by manipulating the presence and relevance of images and text and image motion. We develop and test hypotheses regarding the effects of the manipulated filler interfaces on online users' cognitive absorption dimensions (in particular, focused immersion, temporal dissociation, and heightened enjoyment) through two experimental studies (Study 2 and Study 3). We conduct a nomological analysis to examine relationships between diverse filler interfaces designs, cognitive absorption dimensions, PWT, attitudes (both cognitive and affective appraisals), and Web site use intention (see the research model in Figure 1). The relationships proposed in the model are explained in detail below. 


\begin{tabular}{|l|c|c|}
\hline \multirow{2}{*}{ Table 2. Study 1: Exploratory Factor Analysis } \\
\cline { 2 - 3 } & \multicolumn{2}{|c|}{ Component } \\
\hline FI1 & .179 & TD \\
\hline FI2 & .159 & .902 \\
\hline FI3 & .144 & .917 \\
\hline FI4 & .214 & .954 \\
\hline TD1 & .804 & .928 \\
\hline TD2 & .840 & .278 \\
\hline TD3 & .875 & .190 \\
\hline TD4 & .884 & .092 \\
\hline TD5 & .851 & .115 \\
\hline
\end{tabular}

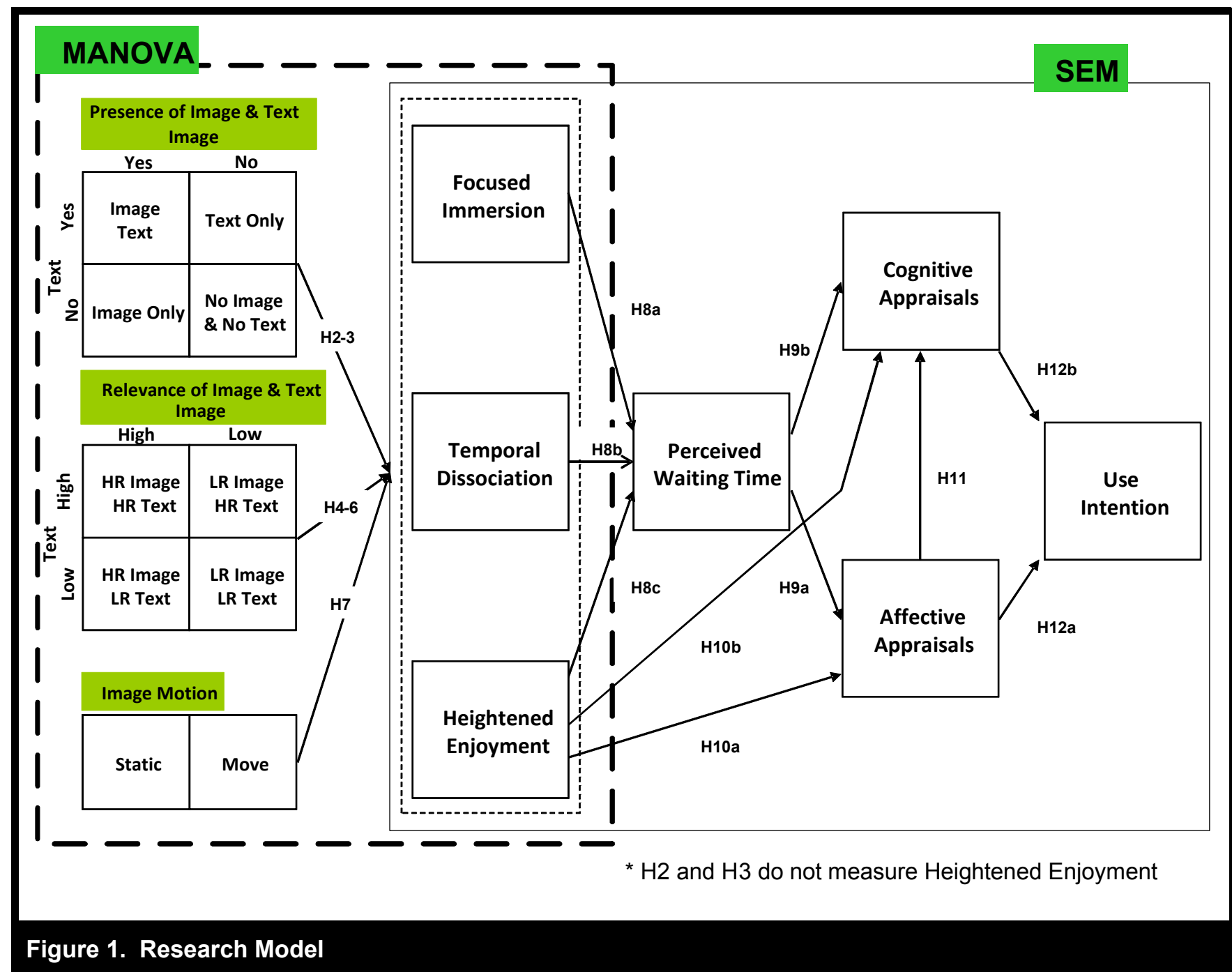




\section{Study 2: Research Hypotheses-Presence of Image/Text}

Prior research using resource allocation theory suggested that the provision of cues (e.g., magazines, music, etc.) can successfully attract users' attention and cause them to become unconscious of the passage of time in various wait contexts such as banking, telephone calls, restaurants, hospitals, and delayed flights (Antonides et al. 2002; Dellaert and Kahn 1999; Katz et al. 1991; Taylor 1994). Such cues constitute distractions that cause individuals to perceive shorter time durations (Durrande-Moreau 1999; Pruyn and Smidts 1998; Ryan and Valverde 2006; Taylor 1994).

In filler interface design, cues such as image and text are pervasively used in commercial Web sites for achieving similar goals (including online advertising). Such textual or image cues are salient visual stimuli that can be detected efficiently in the visual domain (Yantis and Egeth 1999), thus impacting waiting time perceptions. Researchers in the marketing field also investigated the effects of text and images as stimuli in advertising. For instance, Rosbergen et al. (1997) designed four stimuli for a shampoo ad, namely body text, image/picture (female with long hair), headline, and packshot (generic shampoo bottle). Therefore, these reasons prompt us to investigate the presence of text/image as cues in filler interface design and examine their impacts on online waits.

Researchers in HCI and experimental psychology (Janiszewski 1998; Todd and Kramer 1994; Yantis and Egeth 1999; Yantis and Jonides 1984) suggest a significant influence of visual cues in user interface design on drawing users' attention. They point out that an artifact with distinct salient characteristics (e.g., text, images, or both) is highly likely to be selected for viewing and captures more attention than other competing artifacts on user interfaces. In addition, Morrison and Vogel (1998) found that visual presentations with images and text attracted customers' attention more significantly (i.e., higher focused immersion). Other researchers (Appiah 2006; Chaiken and Eagly 1983; Greenwald and Leavitt 1984; Jiang and Benbasat 2005) found that images and text can attract and hold users' attention. Thus, we propose that online users who encounter a filler interface with visual cues will be more immersed in the interaction as compared to those who encounter a filler interface without these cues. H2 reflects this logic.

\section{H2: Filler interfaces with visual design cues lead to higher focused immersion than no-filler interface.}

In addition, based on competition for attention theory, we can expect that a filler interface with visual elements (text, images, or both) will direct individuals' cognitive attention toward the visual stimuli presented on the interface, hence creating a temporal dissociation. This is because, as the theory suggests, salience of an object within the visual field determines the amount of attention an object receives. In addition, when an object is in focal attention (based on stimuli), the human visual system recognizes differences in the intensity of signals generated by the focal object in the visual field (Janiszewski 1998; Steinman and Levinson 1990) and ignores all other competing objects (e.g., waiting time). As human attention span is limited (Woodside and Clokey 1974), salient design elements on filler interfaces (text/image) can become attention-getting objects and thus create temporal dissociation from the passage of time (Zakay 1989).

Thereby, we posit that online users who encounter a filler interface with visual design cues (such as text, images, or both) will be less occupied with the actual passage of time and will perceive more temporal dissociation as compared to individuals who interact with an interface that lacks such visual cues. Thus, we formalize H3:

\section{H3: Filler interfaces with visual design cues lead to higher temporal dissociation than no-filler interface.}

\section{Study 3: Research Hypotheses-Relevance of Image/Text, Image Motion}

According to visual search theory, the relevance of text and images on filler interfaces can also play a major role in influencing time perceptions during online waits. Based on the level of relevance, we distinguish two types of text/ images: generic and relevant. Generic text/images are those that do not deliver direct, beneficial information to their viewers and are task-irrelevant (Bacon and Egeth 1994). From our observation of commercial Web sites, most of them primarily use generic images and/or text on their filler interfaces. For example, inclusion of a flight attendant image or company logo on the filler interface of a travel Web site does not provide customers with specific valuable information. In contrast, relevant text/images on filler interfaces are directly associated with the online search goals and are relevant to the tasks users undertake (Bacon and Egeth 1994). For instance, a filler interface with text or images related to the destination of a flight search provides relevant information for users' goals. Few IS researchers distinguished between taskrelevant and task-irrelevant online search contexts (e.g., Hong et al. 2005). In this study, we investigate the effects of both generic (task-irrelevant) and relevant text/images as design characteristics of filler interfaces on users' perceptions of online wait. 
Researchers using visual search theory (Hong et al. 2005; Hillstorm and Yantis 1994; Lamy and Tsal 1999) suggested that salient objects draw users' attention only when they are perceived as relevant to their tasks. Other authors found similar results. For example, Petty et al. (1983) suggest that people are motivated to exert more cognitive effort (involvement) when the relevance of the message is high. Similarly, Park and Young (1986) argue that when people find information to be personally relevant, they devote considerably more attentional capacity to process that information at a deeper level.

Relevant design elements can also create feelings of focused immersion in the interaction with the interface by attracting users' attention and engaging them in processing the relevant information. As previously noted, simple stimuli (such as text or images) may not be sufficient to attract users' attention. Visual search theorists suggest that attention shifts are critically dependent on the relationship between the stimulus properties and task demands (Folk et al. 1992, p. 1030). Task-relevant stimuli on filler interfaces can provide goaldirected attentional guidance (Bacon and Egeth 1994; Hillstrom and Yantis 1994) during online waits and, in some cases, override stimulus-driven attentional guidance (Bacon and Egeth 1994; Hillstorm and Yantis 1994; Yantis and Egeth 1999). In addition, the relevant characteristics of the interface may also induce a state of deep immersion with the filler interface since the visual stimuli provided on the filler interface are directly related to individuals' behavioral goals (Folk et al. 1992). Thus, we believe that relevant design elements on filler interfaces can stimulate people to involve in processing those elements (Novak et al. 2000) and contribute to creating a state of focused immersion. Hence, we propose H4:

\section{H4: Filler interfaces with relevant design characteristics lead to higher focused immersion than filler interfaces with generic design characteristics.}

As discussed previously, we capture the relevancy of visual stimuli on a filler interface according to whether they are pertinent to the information retrieval experience (taskrelevant). Such relevant textual information or images should draw individuals' attention and distract them from the actual time passage (i.e., temporal dissociation) (Hillstrom and Yantis 1994; Lamy and Tsal 1999). Therefore, we propose that filler interfaces with relevant cues will create more temporal dissociation for an individual than interfaces with generic cues. $\mathrm{H} 5$ is formalized as follows:

\section{H5: Filler interfaces with relevant design characteristics lead to higher temporal dissociation than filler interfaces with generic design characteristics.}

In addition, provision of relevant text or image(s) on the filler interface can make the waiting experience more enjoyable because users perceive pleasantness when they observe the relevant images or read the relevant text that match their search goals. Previous studies suggested that by filling the waiting time with various stimuli, individuals will experience less anger because of the wait (Taylor 1994) and will also be in a more positive mood (Cameron et al. 2003). In contrast, boredom may arise when individuals do not get enough interesting information (Klapp 1986). North et al. (1999) suggested that providing individuals with engaging content during waits or stimuli that fit individuals' expectations could make the waiting experience more interesting. Finally, Cameron et al. (2003) found that fillers such as music positively influenced affective reactions during waits. We argue that task-relevant information on filler interfaces constitutes an engaging content which creates heightened enjoyment during online waits.

In line with these arguments, we posit that relevant design elements on filler interfaces can produce a pleasurable and entertaining experience during online waits. We thus hypothesize:

\section{H6: Filler interfaces with relevant design characteristics lead to more heightened enjoyment than filler interfaces with generic design characteristics.}

As computer graphics and multimedia technologies advanced, the use of animation (e.g., moving images/text, flashing objects, pop-up ads on Web sites, animated products such as viewing a piece of clothing from multiple angles, or animated services such as viewing a slide show of hotel amenities) has become increasingly popular on the Web (Zhang 2000).

In addition to being entertaining (Thomas and Calder 2001) and increasing comprehension through information visualization (Mackinlay et al. 1994), animation attracts users' attention to the animated content on the screen (Diao and Sundar 2004; Fasolo et al. 2006; Hong et al. 2005, 2007; Nielsen 2000). Little IS research has examined the effect of moving image designs on Web sites perceptions (Hong et al. $2005,2007)$. Such research is even scarcer when it comes to investigating the effect of moving images on time perceptions during online waits. Researchers were prompted to conduct studies on the use of moving objects on Web sites and investigate their effects on PWT (Gorn et al. 2004). We believe this is a particularly important area of research because attention is a very scarce resource on the Internet (Davenport and Beck 2001), and the average waiting time online is only two seconds before users switch their attention elsewhere (Nah 2004). 
We use motion effect theory in order to investigate the effect of image motion in filler interface design during online waits. We manipulate image motion by alternating various images during a time interval, similar to an automated slideshow. This type of motion is referred to as tertiary motion (Zettl 1973), which is a sense of motion induced by a series of shots. In this type of motion, a series of images are presented in a quick, sequential succession and the result is an illusion of motion or animation (ChanLin 2000; Detenber and Reeves 1996; Heo 2006). Such sequential image slideshows may be considered one form of animation, which is generally defined as a series of rapidly changing computer screen displays that represent the illusion of motion (ChanLin 2000).

Motion effect theory generally postulates that human attention is very sensitive to stimuli that embed motion. Moving images as stimuli encompass motion (Reeves and Nass 1996) and are visually distinct from other stimuli (e.g., static images) (Hong et al. 2007). Such moving images create a sudden change in human peripheral vision (Girelli and Luck 1997) by disturbing the status quo (Goldstein 1989) and a sudden attention shift or "orienting response" (Lang 1990) occurs. The orienting response is a short-term attention reaction (Lang 2000) evoked by certain stimuli that are either moving, novel, meaningful, or surprising (Diao and Sundar 2004). Research in various domains (including IS) shows that various types of animation (e.g., banner ads, flash) attract users' involuntary attention and direct individuals' concentration toward the moving object even if users are engaged in preassigned tasks (Diao and Sundar 2004; Fasolo et al. 2006; Hong et al. 2005, 2007). In addition, moving images reduce attentional resources available for the main information processing task, thus negatively impacting recall as users need to allocate more mental resources to suppress the distraction (Hong et al. 2005).

Based on motion effect theory, we expect that filler interfaces with moving images would induce a feeling of focused immersion during online waits. This conjecture is perfectly in line with past research using motion effect theory, which postulates that moving images attract users' attention more than static images. Various studies in marketing and advertising (Diao and Sundar 2004; Fasolo et al. 2006; Phillips and Lee 2005), media and communication (Detenber et al. 1998; Ravaja 2004; Simons et al. 2000; Simons et al. 1999) and IS (Hong et al. 2005, 2007; Lai et al. 2009) showed that as compared to static images, moving images captured more attentional resources. Moving images also appeared to sustain attention for longer periods of time than static ones (Simons et al. 2000). Thus, we state $\mathrm{H} 7 \mathrm{a}$ as follows:

H7a: $\quad$ Filler interfaces with moving images lead to higher focused immersion than filler interfaces with static images.
Furthermore, we propose that moving images on a filler interface can induce an orienting response in the form of temporal dissociation during online waits. This claim is based on the following logic: (1) the orienting response caused by moving images is a short-term reaction which fits the filler interface environment and online waits, and (2) moving images create a sudden attention shift on the source of motion, thus attention is distracted away from the passage of time itself. We thus propose the following:

H7b: $\quad$ Filler interfaces with moving images lead to higher temporal dissociation than filler interfaces with static images.

Finally, moving images on a filler interface can also induce a state of heightened enjoyment during online waits. Previous studies using motion effect theory showed that formal properties of stimuli (e.g., moving images) create emotional responses such as arousal, entertainment, or excitement (Lai et al. 2009; Philips and Lee 2005; Reeves et al. 1999; Simons et al. 2000). In fact, Simons et al. (2000) found that moving images were more physiologically arousing than static ones regardless of whether image valence was positive, neutral, or negative. They authors concluded that the impact of image motion on image-induced emotional responses was "inherent to the motion itself" (p. 708). We thus propose the following:

H7c: $\quad$ Filler interfaces with moving images lead to more heightened enjoyment than filler interfaces with static images.

\section{Structural Equation Model: Research Hypotheses-Antecedents and Consequences of PWT}

In this section, we adopt cognitive absorption theory and the literature of users' attitude formation and technology acceptance to develop a nomological network among antecedents of PWT, PWT, and its consequences. We first focus on three dimensions of cognitive absorption (temporal dissociation, focused immersion, and heightened enjoyment) as antecedents of PWT. Then, based on the literature of users' attitude formation and technology acceptance, we select affective and cognitive appraisals about the Web site and their use intention as consequences of PWT.

As we noted previously, during waits, if individuals can engage in distracting tasks that require their attention, they will perceive a shorter waiting duration (Baker and Cameron 1996). This is because people become so absorbed with an activity that all irrelevant perceptions and thoughts simply 
fade away (Csikszentmihalyi 1990). Such focused immersion can be a result of greater focus on nontemporal cues provided on a filler interface (e.g., text or images) (Zakay and Block 2004). Aligned with resource allocation theory, if a concurrent, nontemporal task is more demanding, a person has fewer cognitive resources available to allocate for temporal information processing. Thus, we argue that to the extent a filler interface contains elements that draw users' attention, they will become largely immersed in the interaction with the filler interface and in turn their PWT will be reduced. H8a reflects this logic:

H8a: $\quad$ Greater focused immersion due to a filler interface will negatively relate to PWT in an online environment.

Further, temporal dissociation is an important antecedent of PWT which affects an individual's ability to note passage of time during an interaction with the software (Agarwal and Karahanna 2000). If people achieve a state of temporal dissociation during an online experience (based on various interface designs), they tend to lose their sense of physical time (Csikszentmihalyi 1990), hence they will perceive a shorter time duration (i.e., shorter PWT) (Skadberg and Kimmel 2004). This negative relationship between temporal dissociation and PWT is widely recognized in past wait studies in physical environments (Kellaris and Mantel 1994). Along the same vein, we expect that in online wait contexts, various design elements of a filler interface can induce temporal dissociation for people engaged in an online activity, which in turn will reduce their PWT. Thus,

H8b: $\quad$ Greater temporal dissociation due to a filler interface will negatively relate to PWT in an online environment.

In addition, to the extent that people experience heightened enjoyment because of the design cues embedded in a filler interface, PWT can decline. Past research supports this argument. For example, Hornik (1981) revealed that happy events seemed shorter than somber ones. Fraisse (1984) found that interesting prose passages provided better enjoyment and were judged shorter than boring ones. North and Hargreaves (1996) also pointed out that people perceived less waiting time when they observed stimuli they liked, such as music. Therefore, we propose the following:

H8c: Heightened enjoyment due to a filler interface will negatively relate to $P W T$ in an online environment.

A Web site will likely induce negative attitudes when it is preceded by a lengthy delay (Dellaert and Kahn 1999; Hui and Tse 1996; Rose et al. 2005; Weinberg 2000). Based on recent research in social psychology, attitude consists of two distinct dimensions namely affective appraisals and cognitive appraisals (Kempf 1999; Trafimow and Sheeran 1998; Trafimow et al. 2004; Wolfinbarger and Gilly 2003). Affective appraisals are evaluations based on feelings, emotions, and gut reactions that individuals experience in relation to an attractive object (Breckler 1984; Eagly and Chaiken 1993), while cognitive appraisals refer to the utilitarian aspect of the attitude (Van der Heijden 2002). As hedonic features of information technologies become more and more prevalent, recent IS research has devoted more attention to the dual nature of attitude and suggested that affective and cognitive appraisals should be captured distinctively in research models (Te'eni 2001, p. 253). In the context of online waits, affective appraisals measure hedonic experiences with Web interfaces (e.g., happy, good, relaxed, likable, or satisfactory). Since long waiting times provoke dissatisfaction, anxiety, dislike, and unpleasantness (Baker and Cameron 1996; Guynes 1988; Rose et al. 2005; Taylor 1994), we can predict a negative relationship between PWT and affective appraisals (Rose et al. 2005; Rushinek and Rushinek 1986). Therefore,

\section{H9a: Users'PWT will negatively influence their affective appraisals of a Web site.}

In contrast, cognitive appraisals constitute the utilitarian aspect of the attitude which relates to its value to an individual (Batra and Ahtola 1990; Van der Heijden 2002). They are evaluations based on instrumental beliefs such as usefulness and ease of use (Van der Heijden 2004) as opposed to hedonic considerations (such as feelings, moods, or emotions) (Eagly and Chaiken 1993). In waiting contexts, individuals will evaluate service providers more negatively if PWT is longer than expected (Hui and Tse 1996). Previous studies found a negative relationship between lengthy waiting times and utilitarian evaluations such as performance, convenience, efficiency, and effectiveness (Katz et al. 1991; Pruyn and Smidts 1998; Taylor 1994; Thompson et al. 1996; Tom et al. 1997; Tom and Lucey 1997). Based on these considerations, we propose that PWT will have a negative impact on cognitive appraisals of a Web site. This logic is reflected in $\mathrm{H} 9 \mathrm{~b}$.

H9b: Users' $P W T$ will negatively influence their cognitive appraisals of a Web site.

Heightened enjoyment refers to the pleasurable aspect of the interaction with the software (Agarwal and Karahanna 2000). Previous studies found that hedonic components in physical store design (e.g., color, light, music, store layout) influenced customers' overall pleasant shopping experience as well as 
their positive evaluations of the store (e.g., Yoo et al. 1998). In an online context, incorporating hedonic components on filler interfaces as part of e-business Web sites can increase the enjoyment of the visit and positively affect the overall perceptions toward the site. Studies on technology acceptance also support the influence of enjoyment on cognitive appraisals (i.e., usefulness) (Venkatesh et al. 2002). Therefore, we suggest that if a filler interface is perceived to be enjoyable, users will rate their overall Web experience as both enjoyable and useful. Thus, we propose H10:

H10a: Users' heightened enjoyment relative to a filler interface will positively influence their affective appraisals of a Web site.

H10b: Users' heightened enjoyment relative to a filler interface will positively influence their cognitive appraisals of a Web site.

Further, based on the affect primacy hypothesis (LeDoux 1995; Van der Heijen 2002; Zajonc 1980), affective appraisals arise earlier in the human brain than cognitive appraisals. In other words, specific affective emotions and general mood may impact an individual's instrumental beliefs regarding an attitude object (e.g., Web site). Because heightened enjoyment (intrinsic motivation) was found to be an antecedent of usefulness (extrinsic motivation) in previous technology acceptance literature (e.g., Venkatesh and Bala 2008; Venkatesh et al. 2002), we expect the same relationship in the context of our study. Hence we propose that affective appraisals of a Web site will positively influence the cognitive appraisals of the site.

H11: Users' affective appraisals will positively influence their cognitive appraisals of the Web site.

Finally, we posit that affective and cognitive appraisals have positive impacts on Web site use intention. Previous research proposed a direct relationship between affective and cognitive appraisals and intention to use (Galletta et al. 2006; Hoxmeier and DiCesare 2000; Van der Heijden 2004). This relationship is also supported by the theory of reasoned action (Fishbein and Ajzen 1975) and the technology acceptance model (Davis 1989). To the extent that individuals form positive appraisals of a Web site (both affective and cognitive), they will likely intend to use it. Our last two hypotheses reflect this thinking.

H12a: Users' affective appraisals of a Web site will positively influence their intention to use the Web site.

H12b: Users' cognitive appraisals of a Web site will positively influence their intention to use the Web site.

\section{Research Method}

Two controlled experiments were conducted to examine the effect of (1) the presence of text and images (Study 2) and (2) the interplay among relevance of text, relevance of images, and image motion (Study 3) on individuals' cognitive absorption dimensions, which in turn affects PWT. We further examined the nomological networks between PWT and overall user evaluations of Web sites using AMOS 17.0, a structural equation modeling technique. A total of 355 subjects were recruited for Study 2 and Study 3 (n2=127 and n3 $=228$ respectively). All participants were business school students at a large midwestern U.S. university who had at least a one-time online purchase experience through an online travel site. For all studies, participation was voluntary. Subjects could earn class participation points and an opportunity to win a sweepstake (small cash prize) in return for their participation.

For Studies 2 and 3, we used the same simulated online travel Web site used for Study 1, but developed diverse filler interfaces by manipulating the presence and relevance of image and text, and of image motion.

\section{Study 2: Procedure and Design}

From a design perspective, Study 1 does not provide any specific information with respect to which filler interface design components are more influential in attracting users' attention and distorting time perceptions during online waits. Therefore, Study 2 focuses on the two most popular design components in commercial filler interfaces, namely text and image. We designed four different filler interface conditions (no-filler interface, text only, image only, image and text) and examined how these conditions affected users' perceptions of focused immersion and temporal dissociation during online waits.

Study 2 was conducted one month after Study 1. Subjects were randomly assigned to one of the conditions of a two (image presence condition: no image versus image) by two (text presence condition: no text versus text) betweensubjects design. The no-filler interface condition was the same as that of Study 1. The image only filler interface condition included a Las Vegas main strip image, and the text only condition included recent Las Vegas show information. For the image and text condition, we included the same image and text used for the image only and text only conditions. The experiment was conducted in the same lab setting following the same procedures as Study 1. 


\section{Study 2: Manipulation Check and Results}

The independent variables in Study 2 were the presence of image and the presence of text. The dependent variables were the same as those of Study 1 (focused immersion and temporal dissociation). We first conducted manipulation checks for the presence of image/text. In order to examine whether subjects correctly recognized the presence of image/text shown in a filler interface, we asked each subject three questions (i.e., "What did you see while waiting for the requested results? [Image, Text, Nothing]"). We found that an average of 95 percent of the subjects exactly matched the image and text information for four different presence conditions, implying that the manipulation was successful.

Our results suggest full support for $\mathrm{H} 2$ and partial support for H3. A MANOVA test was conducted in order to test the effect of the presence of image and the presence of text. We found that the Wilks' lambda of the presence of image (Wilks' $\lambda=9.233, \mathrm{p}<.001$ ) and the presence of text (Wilks' $\lambda=7.986, \mathrm{p}<.001$ ) were significant, although the interaction between presence of image and presence of text was not significant (Wilks' $\lambda=1.962, \mathrm{p}>.05$ ) (see Table 3). The subsequent ANOVA test (see Table 3 ) showed that presence of image and presence of text had significant effects on both temporal dissociation and focused immersion, while the interaction effect was not significant.

We further conducted mean comparisons for the four conditions. As shown in Table 4, for focused immersion we found significant differences between the no-filler interface and text only, image only, and image and text conditions respectively. This finding implies that a filler interface with either single design elements (image or text) or combinations of visual elements (text and image) is equally effective in attracting users' attention during online waits. Interestingly, the image and text condition was not significantly more effective than the image only or the text only condition. Although image was slightly more effective than text for focused immersion $\left(\mathrm{Mean}_{\text {Image Only }}=3.77, \mathrm{Mean}_{\text {Text Only }}=3.55\right)$, the difference was also not significant (mean differences $=$ $0.219, \mathrm{p}>.05)$.

For temporal dissociation, we only found significant differences between the no-filler interface condition and image and text condition, and between image only condition and image and text condition. The first finding implies that combinations of visual elements (both text and image) are effective in causing temporal dissociation during online waits. Including only single visual cues (only image or only text) on a filler interface might not significantly induce more temporal dissociation than using no-filler interface. The second finding where text (along with image) was more effective for temporal dissociation than image only is a rather interesting finding. One possible interpretation is that as compared to an image that people can immediately comprehend, it takes more time and effort for people to read both the text and grasp the image's message, thus more temporal dissociation. Otherwise stated, people allocate more attentional resources to reading the text and viewing the image on a filler interface, which may result in higher temporal dissociation than seeing an image alone.

\section{Study 3: Procedure and Design}

Study 2 provides evidence that individuals' temporal dissociation and focused immersion perceptions are significantly affected by the presence of image and text within a filler interface. However, one question still remains: what possible properties or characteristics of image or text (instead of their mere presence) affect users' cognitive absorption perceptions?

We designed Study 3 to tackle this question. We focus on three filler interface design characteristics including relevance of image, relevance of text, and image motion to examine their effects on users' cognitive absorption perceptions of temporal dissociation, focused immersion, and heightened enjoyment. Although customized interface design has been widely recommended in HCI research (e.g., Mathwick et al. 2010), few commercial online travel sites use customized filler interfaces that contain the relevant design components that meet with users' search objectives. In addition, despite the advancement and popularity of Web technologies that allow Web designers to show images in a more animated fashion (e.g., Flash), there is a lack of studies that test the impacts of these technologies in Web site design, and, in particular, filler interface design.

We randomly assigned subjects to one of the conditions of a two (image relevance condition: relevant image versus generic image) by two (text relevance condition: relevant text versus generic text) by two (image motion condition: moving versus static) between-subjects design (see Table 5). Eight different filler interfaces were created for testing our hypotheses (H4-H7). Pretests were conducted to select images and texts used for manipulating the relevance of text and the relevance of image and image motion. We also conducted an exploratory factor analysis to assess the psychometric properties of the dependent variables including focused immersion, temporal dissociation, and heightened enjoyment (see Appendix $\mathrm{C}$ for the details of the pretests). Through pretests, we identified five highly relevant images, five generic images, two highly relevant texts, and two generic texts for 


\section{Table 3. Study 2: Tests of Between-Subjects Effect}

\begin{tabular}{|l|l|r|r|r|r|r|}
\hline \multicolumn{1}{c|}{ Source } & \multicolumn{1}{c|}{ Dependent Variable } & Sum of Squares & \multicolumn{1}{c|}{ df } & \multicolumn{1}{c|}{$\begin{array}{c}\text { Mean } \\
\text { Square }\end{array}$} & F & Sig. \\
\hline \multirow{2}{*}{ Intercept } & Focused Immersion & 1568.231 & 1 & 1568.231 & 915.222 & .000 \\
\cline { 2 - 7 } & Temporal Dissociation & 1613.024 & 1 & 1613.024 & 976.386 & .000 \\
\hline \multirow{2}{*}{ Presence of Image } & Focused Immersion & 26.962 & 1 & 26.962 & 15.735 & .000 \\
\cline { 2 - 7 } & Temporal Dissociation & 8.867 & 1 & 8.867 & 5.368 & .022 \\
\hline \multirow{2}{*}{ Presence of Text } & Focused Immersion & 15.657 & 1 & 15.657 & 9.138 & .003 \\
\cline { 2 - 7 } & Temporal Dissociation & 15.803 & 1 & 15.803 & 9.566 & .002 \\
\hline \multirow{2}{*}{$\begin{array}{l}\text { Presence of Image } \\
\text { Presence of Text }\end{array}$} & Focused Immersion & 2.727 & 1 & 2.727 & 1.591 & .210 \\
\hline \multirow{2}{*}{ Error } & Temporal Dissociation & 2.852 & 1 & 2.852 & 1.726 & .191 \\
\hline \multirow{2}{*}{ Total } & Focused Immersion & 210.760 & 123 & 1.713 & & \\
\cline { 2 - 7 } & Temporal Dissociation & 203.200 & 123 & 1.652 & & \\
\hline
\end{tabular}

Table 4. Study 2: Mean Comparison Between No Filler, Text Only, Image Only, and Image and Text Condition

\begin{tabular}{|c|c|c|c|c|}
\hline Manipulation & No filler & Text Only & Image Only & Image and Text \\
\hline Mean & 2.56 & 3.55 & 3.77 & 4.18 \\
\hline $\bar{n}$ & 30 & 32 & 31 & 34 \\
\hline No filler & & $-0.996(\mathbf{0 . 0 3 4 )}$ & $-1.216(\mathbf{0 . 0 0 6})$ & $-1.625(0.000)$ \\
\hline Text Only & $0.996(\mathbf{0 . 0 3 4})$ & & $-0.219(0.931)$ & $-0.629(0.288)$ \\
\hline Image Only & $1.216(\mathbf{0 . 0 0 6 )}$ & $0.219(0.931)$ & & $-0.409(0.663)$ \\
\hline Image and Text & $1.625(\mathbf{0 . 0 0 0 )}$ & $0.629(0.288)$ & $0.409(0.663)$ & \\
\hline \multicolumn{5}{|c|}{ b) Temporal Dissociation } \\
\hline Manipulation & No filler & Text Only & Image Only & Image and Text \\
\hline Mean & 3.10 & 3.51 & 3.33 & 4.34 \\
\hline $\mathrm{n}$ & 30 & 32 & 31 & 34 \\
\hline No filler & & $-0.406(0.672)$ & $-0.229(0.922)$ & $-1.235(\mathbf{0 . 0 0 3 )}$ \\
\hline Text Only & $0.406(0.672)$ & & $0.177(0.960)$ & $-0.829(0.082)$ \\
\hline Image Only & $0.229(0.922)$ & $-0.177(0.960)$ & & $-1.006(\mathbf{0 . 0 0 2 )}$ \\
\hline Image and Text & $1.235(\mathbf{0 . 0 0 3 )}$ & $0.829(0.922)$ & $1.006(\mathbf{0 . 0 0 2})$ & \\
\hline
\end{tabular}

Table 5. Study 3: Research Design

\begin{tabular}{|l|l|l|c|c|c|}
\hline \multirow{2}{*}{\multicolumn{2}{|c|}{}} & \multicolumn{4}{c|}{ Relevance of Image } \\
\cline { 3 - 6 } & \multicolumn{2}{|c|}{ Relevant } & \multicolumn{2}{c|}{ Generic } \\
\cline { 3 - 6 } & Static & Move & Static & Move \\
\hline $\begin{array}{l}\text { Relevance of } \\
\text { Text }\end{array}$ & Relevant & $n=26$ & $n=27$ & $n=27$ & $n=29$ \\
\cline { 2 - 6 } & Generic & $n=30$ & $n=27$ & $n=29$ & $n=33$ \\
\hline
\end{tabular}


designing filler interfaces. In addition, we found that all dependent variables had strong psychometric properties. All factor loading scores were greater than .728 and Cronbach's alpha values were all greater than .929 .

\section{Study 3: Manipulation Check and Results}

Before conducting the data analysis, we performed manipulation checks to examine whether the relevance of image and the relevance of text and image motion were successfully manipulated. In order to establish the relevance of text/image, participants responded to five relevance questions (e.g., "The image/text shown in the filler interface was informative/ useful/helpful.") on a five point Likert-type scale. An ANOVA test was used to verify the success of the manipulation. The mean difference for generic and relevant images and text was significant $\left(\mathrm{Mean}_{\mathrm{gen}}=3.90, \mathrm{Mean}_{\mathrm{rel}}=4.41, \mathrm{~F}_{1,226}\right.$ $=7.491, \mathrm{p}<.01$ for image; Mean $_{\text {gen }}=3.95$, Mean $_{\text {rel }}=4.36$, $\mathrm{F}_{1,226}=4.8781, \mathrm{p}<.05$ for text) implying the successful manipulation of relevance. ${ }^{4}$ We also checked whether the image motion was successfully manipulated. We compared the mean difference between image motion (Mean $=4.737$, $\mathrm{SD}=1.28)$ and static image $($ Mean $=3.92, \mathrm{SD}=1.481)$ using two perceived image motion items (see Appendix B). The ANOVA test results demonstrated significant statistical differences between the two image motion conditions ( $\mathrm{F}=$ $19.647, \mathrm{p}<.001)$ in support of the successful manipulation of image motion. An exploratory factor analysis showed that all dependent variables (temporal dissociation, focused immersion, and heightened enjoyment) had high reliabilities (at least .929 ) and high factor loading scores (at least .728).

A MANOVA test was conducted in order to test the relevance and motion effects. We found that the Wilks' lambda of image relevance $\left(\mathrm{F}_{1,216}=4.300, \mathrm{p}<.01\right)$, text relevance $\left(\mathrm{F}_{1,216}\right.$ $=6.839, \mathrm{p}<.001)$, and image motion $\left(\mathrm{F}_{1,216}=10.319, \mathrm{p}<\right.$ $.001)$ were significant, but their interaction effects were not (perceived relevance of image $\times$ perceived relevance of text, $\mathrm{F}=0.819, \mathrm{p}>.05 ;$ perceived relevance of image $\times$ image motion, $\mathrm{F}=0.300, \mathrm{p}>.05$; perceived relevance of text $\times$ image motion, $\mathrm{F}=0.837, \mathrm{p}>.05$; perceived relevance of image $\times$ perceived relevance of text $\times$ image motion, $F=$ $0.218, \mathrm{p}>.05)$.

The subsequent ANOVA tests (see Table 6) showed that image relevance, text relevance, and image motion had significant effects on temporal dissociation, focused immersion, and heightened enjoyment while the interaction effects were insignificant for all dependent variables. Thus, we found support for $\mathrm{H} 4-\mathrm{H} 7$.

\footnotetext{
${ }^{4}$ A five-point Likert scale was used for measuring perceived relevance.
}

\section{Mediation Tests}

Finally, following the four-step procedure proposed by Baron and Kenny (1986), we conducted mediation tests for Study 2 and Study 3 to examine whether three dimensions of cognitive absorption (temporal dissociation, focused immersion, and heightened enjoyment) fully mediated the relationships between filler interface designs and $\mathrm{PWT}^{5}$ (see Table 7). We found that for Study 2, both focused immersion and temporal dissociation fully mediated the relationship. Meanwhile, focused immersion and heightened enjoyment fully mediated the relationship, while temporal dissociation partially mediated this relationship in Study 3. To examine the partial mediation of temporal dissociation, we redid the regression analyses. First, we ran a regression by including only temporal dissociation and PWT and found that their relationships were significant. Then, we ran the regression again by including focused immersion, temporal dissociation, and heightened enjoyment and found that temporal dissociation was not significant. One possible reason for the partial mediation of temporal dissociation may be that the effects of focused immersion and heightened enjoyment on PWT were dominant over temporal dissociation. ${ }^{6}$

\section{Structural Equation Model (SEM) Analysis}

The main objective of the structural equation model analysis was to examine the antecedents of PWT, PWT itself, and users' overall perceptions of the Web site and use intention.

We pooled the data gathered through the surveys used in Study 2 and Study 3, and analyzed them using AMOS 17.0. Before using the pooled data of 355 user responses (Study 2: $\mathrm{n}=127$; Study 3: $\mathrm{n}=228$ ), we compared all demographic information of the two datasets and found no significant differences with regard to gender $\left(\mathrm{Mean}_{\text {study2 }}=1.54, \mathrm{Mean}_{\text {study } 3}=\right.$ $1.53, \mathrm{~F}=0.011, \mathrm{p}>.05)$, age $\left(\mathrm{Mean}_{\text {study } 2}=20.13, \mathrm{Mean}_{\text {study } 3}\right.$ $=20.21, \mathrm{~F}=0.115, \mathrm{p}>.05)$, online travel site experience $\left(\mathrm{Mean}_{\text {study2 }}=3.98, \mathrm{Mean}_{\text {study3 }}=4.03, \mathrm{~F}=0.259, \mathrm{p}>.05\right)$, and Internet use experience $\left(\mathrm{Mean}_{\text {study } 2}=3.85, \mathrm{Mean}_{\text {study3 }}=3.91\right.$, $\mathrm{F}=1.617, \mathrm{p}>.05)$.

\footnotetext{
${ }^{5}$ Although Study 2 and Study 3 did not hypothesize and test the relationship between filler interface designs and PWT, we assessed PWT using the three scales developed by Gorn et al. (2004) for the subsequent nomological networks analysis. Thus, we can test the mediation effect of cognitive absorption. However, we only examined the mediating effects of each independent variable without examining the combined effects.

${ }^{6}$ In this study, we conducted the mediating test for each independent variable without considering the combined interaction effects which is a limitation of this study.
} 


\begin{tabular}{|c|c|c|c|c|c|c|}
\hline Source & DV & SS & df & MS & $\mathbf{F}$ & Sig \\
\hline \multirow{3}{*}{ Perceived relevance of text } & TD & 16.561 & $(1,220)$ & 16.561 & 11.242 & .001 \\
\hline & $\mathrm{FI}$ & 25.101 & $(1,220)$ & 25.101 & 13.329 & .000 \\
\hline & $\mathrm{HE}$ & 18.320 & $(1,220)$ & 18.320 & 11.504 & .001 \\
\hline \multirow{3}{*}{ Perceived relevance of image } & TD & 14.592 & $(1,220)$ & 14.592 & 9.905 & .002 \\
\hline & $\mathrm{FI}$ & 9.888 & $(1,220)$ & 9.888 & 5.251 & .023 \\
\hline & $\mathrm{HE}$ & 12.622 & $(1,220)$ & 12.622 & 7.926 & .005 \\
\hline \multirow{3}{*}{ Image motion } & TD & 30.535 & $(1,220)$ & 30.535 & 20.727 & .000 \\
\hline & $\mathrm{FI}$ & 38.137 & $(1,220)$ & 38.137 & 20.251 & .000 \\
\hline & $\mathrm{HE}$ & 29.025 & $(1,220)$ & 29.025 & 18.226 & .000 \\
\hline \multirow{3}{*}{$\begin{array}{l}\text { Perceived relevance of text } \times \text { Perceived relevance of } \\
\text { image }\end{array}$} & TD & 1.457 & $(1,220)$ & 1.457 & 0.989 & .321 \\
\hline & $\mathrm{FI}$ & .331 & $(1,220)$ & 0.331 & 0.176 & .675 \\
\hline & $\mathrm{HE}$ & .001 & $(1,220)$ & 0.001 & 0.001 & .982 \\
\hline \multirow{3}{*}{ Perceived relevance of text $\times$ Image motion } & TD & .144 & $(1,220)$ & $\overline{0.144}$ & 0.098 & .755 \\
\hline & $\mathrm{FI}$ & .494 & $(1,220)$ & 0.494 & 0.262 & .609 \\
\hline & $\mathrm{HE}$ & .064 & $(1,220)$ & 0.064 & 0.040 & .841 \\
\hline \multirow{3}{*}{ Perceived relevance of image $\times$ Image motion } & TD & .054 & $(1,220)$ & 0.054 & 0.037 & .848 \\
\hline & $\mathrm{FI}$ & 3.655 & $(1,220)$ & 3.655 & 1.941 & .165 \\
\hline & $\mathrm{HE}$ & 1.604 & $(1,220)$ & 1.604 & 1.007 & .317 \\
\hline \multirow{3}{*}{$\begin{array}{l}\text { Perceived relevance of text } \times \text { Perceived relevance of } \\
\text { image } \times \text { Image motion }\end{array}$} & TD & .008 & $(1,220)$ & 0.008 & 0.005 & .942 \\
\hline & $\mathrm{FI}$ & .928 & $(1,220)$ & 0.928 & 0.493 & .483 \\
\hline & $\mathrm{HE}$ & .470 & $(1,220)$ & 0.470 & 0.295 & .587 \\
\hline
\end{tabular}

\begin{tabular}{|c|c|c|c|c|}
\hline & Step 1 & Step 2 & Step 3 & Step 4 \\
\hline Study 2 & $\begin{array}{l}\cdot \text { Image Presence } \rightarrow \text { PWT } \\
t=2.489, p<0.05 \\
\cdot \text { Text Presence } \rightarrow \text { PWT } \\
t=3.651, p<0.001\end{array}$ & $\begin{array}{l}\text { - Image Presence } \rightarrow \mathrm{FI} \\
\mathrm{t}=3.911, \mathrm{p}<0.001 \\
\text { - Text Presence } \rightarrow \mathrm{FI} \\
\mathrm{t}=2.987, \mathrm{p}<0.01 \\
\text { - Image Presence } \rightarrow \text { TD } \\
\mathrm{t}=2.363, \mathrm{p}<0.05 \\
\text { - Text Presence } \rightarrow \text { TD } \\
\mathrm{t}=3.115, \mathrm{p}<0.01\end{array}$ & $\begin{array}{l}\cdot \mathrm{FI} \rightarrow \mathrm{PWT} \\
\mathrm{t}=4.096, \mathrm{p}<0.001 \\
\cdot \mathrm{TD} \rightarrow \mathrm{PWT} \\
\mathrm{t}=8.839, \mathrm{p}<0.001\end{array}$ & $\begin{array}{l}\cdot \text { Image Presence } \rightarrow \text { PWT } \\
t=0.234, p>0.05 \\
\text { - Text Presence } \rightarrow \text { PWT } \\
t=1.413, p>0.05 \\
\cdot \text { FI } \rightarrow \text { PWT } \\
t=3.505, p<0.01 \\
\text { - TD } \rightarrow \text { PWT } \\
t=8.199, p<0.001\end{array}$ \\
\hline Study 3 & $\begin{array}{l}\cdot \text { Image Relevance } \rightarrow \text { PWT } \\
t=3.379, p<0.001 \\
\text { - Text Relevance } \rightarrow \text { PWT } \\
t=3.827, p<0.001 \\
\text { - Image Motion } \rightarrow \text { PWT } \\
t=4.406, p<0.001\end{array}$ & $\begin{array}{l}\cdot \text { - Image Relevance } \rightarrow \mathrm{FI} \\
\mathrm{t}=2.324, \mathrm{p}<0.05 \\
\cdot \text { Text Relevance } \rightarrow \mathrm{FI} \\
\mathrm{t}=3.672, \mathrm{p}<0.001 \\
\cdot \text { Image Motion } \rightarrow \mathrm{FI} \\
\mathrm{t}=4.467, \mathrm{p}<0.001 \\
\text { - Image Relevance } \rightarrow \mathrm{TD} \\
\mathrm{t}=3.135, \mathrm{p}<0.01 \\
\cdot \text { Text Relevance } \rightarrow \mathrm{TD} \\
\mathrm{t}=3.344, \mathrm{p}<0.001 \\
\cdot \text { Image Motion } \rightarrow \mathrm{TD} \\
\mathrm{t}=4.609, \mathrm{p}<0.001 \\
\cdot \text { Image Relevance } \rightarrow \mathrm{HE} \\
\mathrm{t}=2.820, \mathrm{p}<0.01 \\
\cdot \text { Text Relevance } \rightarrow \mathrm{HE} \\
\mathrm{t}=3.368, \mathrm{p}<0.01 \\
\cdot \text { Image Motion } \rightarrow \mathrm{HE} \\
\mathrm{t}=4.351, \mathrm{p}<0.00\end{array}$ & $\begin{array}{l}\cdot \mathrm{FI} \rightarrow \mathrm{PWT} \\
\mathrm{t}=4.903, \mathrm{p}<0.001 \\
\cdot \mathrm{TD} \rightarrow \mathrm{PWT} \\
\mathrm{t}=1.599, \mathrm{p}>0.05 \\
\cdot \mathrm{HE} \rightarrow \text { PWT } \\
\mathrm{t}=7.384, \mathrm{p}<0.001\end{array}$ & $\begin{array}{l}\cdot \text { - Image Relevance } \rightarrow \text { PWT } \\
t=1.468, p>0.05 \\
\text { - } \text { Text Relevance } \rightarrow \text { PWT } \\
t=1.551, p>0.05 \\
\text { - Image Motion } \rightarrow \text { PWT } \\
\text { t }=1.227, p>0.05 \\
\text { - FI } \rightarrow \text { PWT } \\
t=4.512, p<0.001 \\
\text { - TD } \rightarrow \text { PWT } \\
t=.889, p>0.05 \\
\text { - HE } \rightarrow \text { PWT } \\
t=6.864, p<0.001\end{array}$ \\
\hline
\end{tabular}


In addition to items used for temporal dissociation, focused immersion, and heightened enjoyment, participants of Studies 2 and 3 also answered questions measuring PWT, cognitive and affective appraisals, and Web site use intention (see Appendix B). The PWT measure used three items from Gorn et al. (2004). Affective appraisals employed five items from Fishbein and Ajzen (1975). The four cognitive appraisals items were based on Lee and Kozar (2009). Finally, the three use intention items were adopted from Palmer (2002).

\section{Measurement Model Analysis}

We conducted a confirmatory factor analysis (CFA) to (1) validate the psychometric properties of the instrument, (2) examine whether the measurement model achieved an acceptable goodness-of-fit, and (3) investigate its unidimensionality, convergent and discriminant validity, and reliability. The overall goodness-of-fit for the model reached the cut-off value (Hair et al. 2006). The $\chi 2 / \mathrm{df}$ was 2.212 and below the desired threshold of 3.0. The root mean squared error of approximation (RMSEA) was .059, below the .08 cut-off level. In addition, both the normed fit index $(\mathrm{NFI}=.941)$ and confirmatory fit index (CFI $=.967)$ were greater than the required value of .90. Finally, goodness-of-fit index (GFI $=$ $.870)$ and adjusted GFI (.840) were greater than the threshold value of .80 . Thus, we can conclude that the measurement model fitted the data well.

Fornell and Larcker (1981) suggested three criteria for convergent validity: (1) all indicator factor loadings $(\lambda)$ should be significant at $p<.05$ and exceed .7, (2) composite reliabilities should exceed .7, and (3) the average variance extracted (AVE) for each construct should exceed the variance due to the measurement error for that construct. As shown in Table 8, all factor loadings in the CFA model exceeded .7 and were significant at $\mathrm{p}=.001$. The composite reliabilities ranged between .881 and .967 , while the AVE values were well above the cut-off value of .50 and greater than the variance due to measurement error. Therefore, it is evident that the model meets all three conditions for convergent validity.

To assess discriminant validity, we constrained the estimated correlation parameters $\left(\varphi_{i j}\right)$ between constructs to 1.0 and performed chi-square difference tests on the values obtained for the constrained and unconstrained models. As a result, we found significant chi-square differences at $\mathrm{p}<.05$, in support of discriminant validity of these constructs. As shown in Table 9, all constructs had a stronger correlation with their own measures than with those of other constructs. All correlations between constructs were less than . 7 and less than the square root value of the AVE, also in support of discriminant validity. Finally, as shown in Table 8, the Cronbach's alphas of all constructs, which were all greater than or equal to .879 , indicated the high reliability of the items used for each construct.

\section{Structural Model Analysis}

Figure 2 depicts the structural model analysis results, including path loadings for all hypothesized relationships.

The model successfully explained a large amount of variance in PWT $\left(\mathrm{R}^{2}=0.508\right)$ and overall Web site evaluations $\left(\mathrm{R}^{2}=\right.$ 0.505 for Affective Appraisals; $R^{2}=0.441$ for Cognitive Appraisals and $\mathrm{R}^{2}=0.445$ for Use Intention). Focused immersion (H8a: $\lambda=-0.397, \mathrm{p}<.001$ ), temporal dissociation (H8b: $\lambda=-0.110, \mathrm{p}<.01)$, and heightened enjoyment (H8c: $\lambda=-0.347, \mathrm{p}<.001)$ all strongly influenced PWT and explained a large proportion of its variance $\left(\mathrm{R}^{2}=.508\right)$. In addition, PWT exhibited a strong influence on affective appraisals (H9a: $\lambda=-0.375, \mathrm{p}<.001$ ) and cognitive appraisals (H9b: $\lambda=-0.450, p<.001)$ of the online travel site. Heightened enjoyment experienced through a filler interface had a significant effect on affective appraisals (H10a: $\lambda=0.413, p<.001$ ) but not on cognitive appraisals (H9a: $\lambda=-0.046, p>.05$ ). In turn, affective appraisals revealed significant effects on cognitive appraisals (H9: $\lambda=$ $.324, \mathrm{p}<.001)$. Finally, both affective and cognitive appraisals significantly influenced Web site use intentions (H12a: $\lambda=.389, \mathrm{p}<.001 ; \mathrm{H} 12 \mathrm{~b}: \lambda=.363, \mathrm{p}<.001)$.

Since this study was cross-sectional in nature, we examined the presence of the common method bias (CMB) using a technique recommended by Podsakoff et al. (2003), controlling for the effects of an unmeasured latent methods factor. Our test results revealed that the significance of all relationships in the nomological network was unchanged. In addition, the overall goodness-of-fit measures for the models were not significantly different, indicating that biases were not substantial. ${ }^{7}$

\section{Discussion}

Using the theories of resource allocation, cognitive absorption, and competition for attention, visual search, and motion effect, this study investigated the influence of filler interface designs on online wait. Three controlled experiments and

\footnotetext{
${ }^{7}$ Because the model was under-identified, we conducted paired control for the latent variables to examine the common method bias.
} 


\begin{tabular}{|c|c|c|c|c|}
\hline Construct & $\begin{array}{c}\text { Item } \\
\text { Loadings }\end{array}$ & $\begin{array}{c}\text { Cronbach's } \\
\text { Alpha }\end{array}$ & $\begin{array}{r}\text { Composite } \\
\text { Reliability }\end{array}$ & $\begin{array}{c}\text { Average Variance } \\
\text { Extracted }\end{array}$ \\
\hline \multirow{4}{*}{ Focused Immersion } & 0.867 & \multirow{4}{*}{0.953} & \multirow{4}{*}{0.952} & \multirow{4}{*}{0.832} \\
\hline & 0.881 & & & \\
\hline & 0.967 & & & \\
\hline & 0.930 & & & \\
\hline \multirow{5}{*}{ Time Distortion } & 0.847 & \multirow{5}{*}{0.937} & \multirow{5}{*}{0.938} & \multirow{5}{*}{0.753} \\
\hline & 0.924 & & & \\
\hline & 0.858 & & & \\
\hline & 0.846 & & & \\
\hline & 0.860 & & & \\
\hline \multirow{4}{*}{ Heightened Enjoyment } & 0.908 & \multirow{4}{*}{0.952} & \multirow{4}{*}{0.948} & \multirow{4}{*}{0.822} \\
\hline & 0.970 & & & \\
\hline & 0.913 & & & \\
\hline & 0.829 & & & \\
\hline \multirow{3}{*}{ Perceived Waiting Time } & 0.947 & \multirow{3}{*}{0.966} & \multirow{3}{*}{0.967} & \multirow{3}{*}{0.907} \\
\hline & 0.979 & & & \\
\hline & 0.930 & & & \\
\hline \multirow{4}{*}{ Cognitive Appraisals } & 0.948 & \multirow{4}{*}{0.963} & \multirow{4}{*}{0.964} & \multirow{4}{*}{0.870} \\
\hline & 0.971 & & & \\
\hline & 0.869 & & & \\
\hline & 0.940 & & & \\
\hline \multirow{5}{*}{ Affective Appraisals } & 0.923 & \multirow{5}{*}{0.963} & \multirow{5}{*}{0.963} & \multirow{5}{*}{0.840} \\
\hline & 0.955 & & & \\
\hline & 0.864 & & & \\
\hline & 0.948 & & & \\
\hline & 0.888 & & & \\
\hline \multirow{3}{*}{ Use Intention } & 0.891 & \multirow{3}{*}{0.879} & \multirow{3}{*}{0.881} & \multirow{3}{*}{0.712} \\
\hline & 0.789 & & & \\
\hline & 0.849 & & & \\
\hline
\end{tabular}

\begin{tabular}{|c|c|c|c|c|c|c|c|c|c|}
\hline & Mean & SD & FI & TD & HE & PWT & AA & CA & UI \\
\hline Focused immersion & 3.920 & 1.344 & 0.912 & & & & & & \\
\hline Temporal dissociation & 3.727 & 1.460 & 0.295 & 0.867 & & & & & \\
\hline Heightened enjoyment & 4.022 & 1.414 & 0.242 & 0.652 & 0.906 & & & & \\
\hline Perceived Waiting Time & 2.680 & 1.645 & -0.323 & -0.689 & -0.651 & 0.952 & & & \\
\hline Affective Appraisals & 4.992 & 1.255 & 0.174 & 0.575 & 0.658 & -0.644 & 0.933 & & \\
\hline Cognitive Appraisals & 4.486 & 1.425 & 0.191 & 0.549 & 0.450 & -0.619 & 0.583 & 0.916 & \\
\hline Use Intention & 3.988 & 1.156 & 0.244 & 0.547 & 0.525 & -0.576 & 0.597 & 0.590 & 0.844 \\
\hline
\end{tabular}

*Values in diagonal represent the square root of the average variance extracted. 


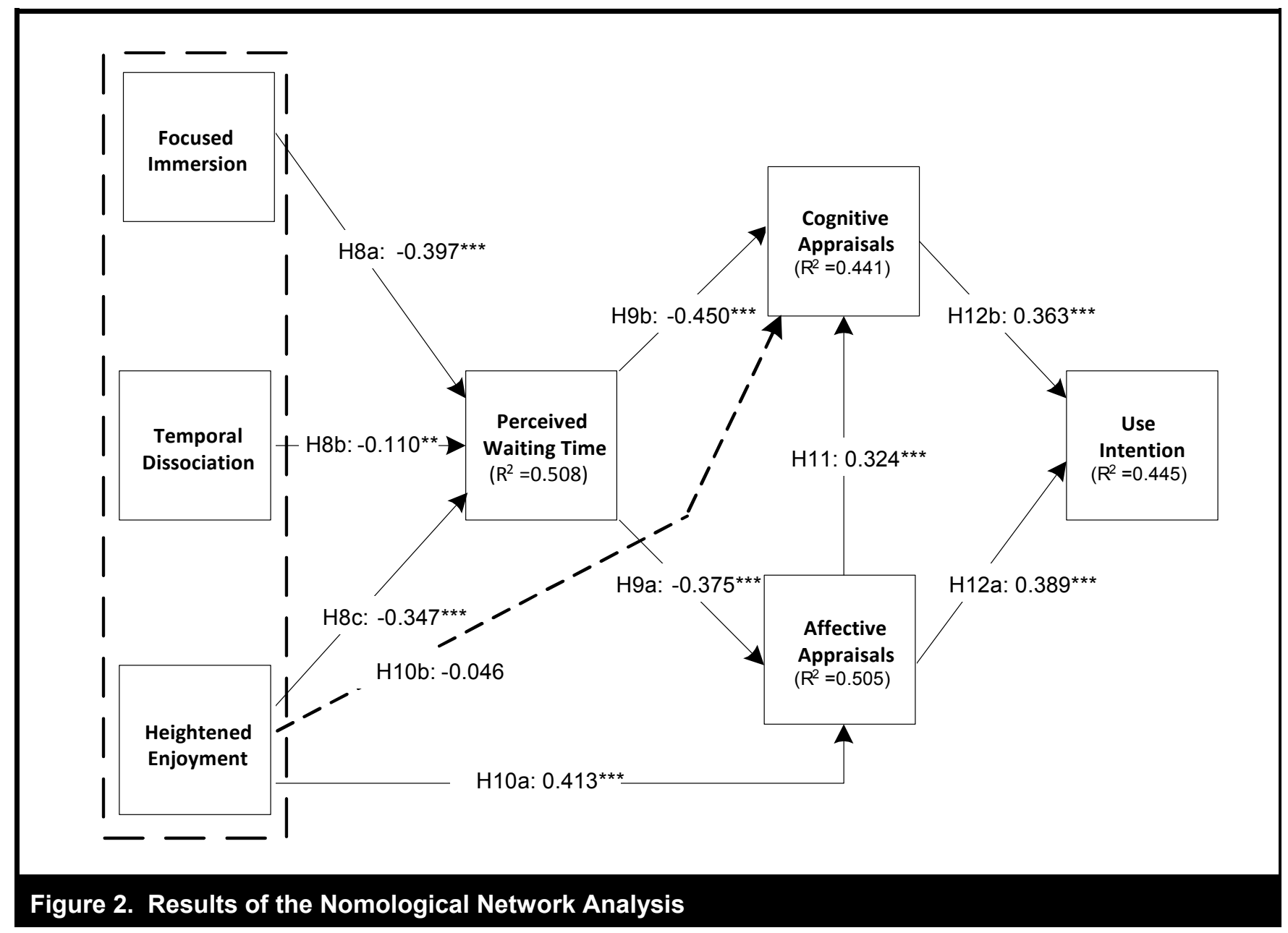

structural equation modeling analysis were conducted to confirm the relationships between filler interface designs and waiting time perceptions. Specifically, we showed how manipulations of various filler interface designs influenced cognitive absorption variables, namely focused immersion, temporal dissociation, and heightened enjoyment. In addition, we investigated how these cognitive perceptions affected PWT online, which in turn triggered individuals' affective and cognitive appraisals of the overall Web site and use intention. To the best of our knowledge, this is the first study in an online waiting context that explores the influence of diverse filler interface designs on PWT. This study is also the first attempt to propose a theoretical model that links filler interface design, cognitive absorption perceptions, PWT, and Web site evaluations. Our proposed model exhibited good psychometric properties and explained significant amounts of variance of all endogenous variables (approximately 51 percent, 51 percent, 44 percent, and 45 percent for PWT, affective and cognitive appraisals, and use intention, respectively).
Results from exploratory Study 1 confirmed our initial intuition that users experience more focused immersion and temporal dissociation when they see a filler interface while waiting online. This finding firmly established the filler interface as an important tool to manipulate online users' cognitive time perceptions and provided a stronger empirical basis for deeper investigations into the various design characteristics of filler interfaces.

The two follow-up studies (Study 2 and Study 3 ) corroborated Study 1's results and also provided additional evidence for various designs of filler interface and their role in manipulating individuals' time perceptions during online waits. Results from Study 2 suggested that online users experience more focused immersion when viewing a filler interface (with either text or image, and a combination of text and image) than not seeing a filler interface while waiting online. The interaction effect between text and image was insignificant (as compared to the text/image only conditions), suggesting that 
a filler interface with single design elements (either text or image) would be sufficient in manipulating users' perceptions of focused immersion during online waits. Thus, our results suggest that combinations of visual elements on a filler interface are not necessarily better in manipulating online users' focused immersion during waits.

With regard to temporal dissociation, results showed that online users experienced significant temporal dissociation when presented with a filler interface but only in the case when a combination of visual cues (both text and image) was shown on the interface. These results also suggest that visual cues alone (either text or image) included on filler interfaces are not sufficient to elicit temporal dissociation during online waits as compared to the no-filler interface condition. Further, there was no significant difference in temporal dissociation between users viewing a filler interface with text only and users viewing a filler interface with both text and image. However, we found a significant difference in temporal dissociation between the filler interface with image only and the filler interface with both text and image. These results suggest that combination of design elements on filler interfaces (text and image) works significantly better in creating temporal dissociation than single elements (image only). One possible interpretation is that as compared to an image that people can immediately comprehend, it takes more time and effort for people to read both the text and grasp the image's message, thus more temporal dissociation.

Our results also imply that certain single design elements (text) may be as efficient as combination of elements (text and image) in distorting the time passage. One possible interpretation for the superiority of text (over image) as single visual cue in filler interface design could be that users may tend to spend more time on reading the text (which in turn will cause more temporal dissociation) rather than watching an image that is easy to grasp and comprehend (thus less temporal dissociation for image). In sum, image alone on filler interface designs may not create temporal dissociation during online waits. Either text alone or combination of visual cues (text and image) as design characteristics of filler interfaces can produce temporal dissociation during online waits.

Study 3 also offered interesting results. With the inclusion of various filler interface design characteristics (relevant text, relevant image, or image motion), users seemed to experience more focused immersion, temporal dissociation, and heightened enjoyment while waiting online. Our results provide theoretical justification for practitioners to design filler interfaces that include text or images relevant to online users' search tasks. At the same time, displaying moving images is also a good tactic to manipulate online users' cognitive perceptions of time during waits.
With regard to synergy effects, our results indicated no interaction effect among the presence of relevant text, relevant image, and image motion on a filler interface. This is a very interesting and important finding which might work against the conventional thinking that more is better. In other words, results from this study suggest that designing a filler interface with any single design component (either relevant text or relevant image or image motion) has similar effects on users' cognitive absorption perceptions. Therefore, interface designers can focus their design efforts (and limited resources) on any of the three design elements in order to manipulate PWT online. As shown in this study, combinations of such design elements may not necessarily be better in PWT manipulations than each element used alone.

\section{Theoretical Contributions}

Our theoretical model, controlled experiments, and structural equation modeling analysis in an online wait context make several contributions to the IS literature. First, by systematically investigating online wait perceptions in an e-business environment, we expand the theoretical boundaries of online wait research with a focus on PWT. Although researchers (e.g., Gorn et al. 2004) have called for work that examined wait perceptions and behaviors of online users, few studies responded to this call, which has severely limited our understanding of the online wait phenomenon. We proposed and tested a research model and suggested ways to proactively manage PWT online.

Second, we identify a Web-specific medium (i.e., filler interface) that has not received much attention in the IS literature (Benbasat 2010). Yet, filler interfaces are prevalent on the Internet in various contexts, including digital libraries, software installations, product searches, and music downloads. Despite their widespread use, research remains scarce regarding their impact on manipulating time perceptions in an online environment. While there are abundant HCI studies that address interface design in general, this study is one of the first to investigate specific design issues related to the filler interface. This study used HCI theories (i.e., competition for attention, visual search, and motion effect) to design the various filler interfaces and showed how these theories with roots in cognitive psychology and physiology apply to designs of filler interfaces that successfully manipulate waiting time perceptions online. This study serves as a starting point for further research into other design components of filler interfaces (e.g., progress bars, background colors, pop-ups, fonts, and typefaces) and their impacts on PWT. 
Third, we bridge a gap in the IS literature by developing a theoretical model of online wait. Without a theoretical foundation, previous studies on online wait simply assessed objective or subjective amounts of online waiting time (e.g., Nah 2004) or treated online wait as one factor out of many factors affecting online behaviors (Galletta et al. 2006; Palmer 2002). In this study, we integrate multiple theories from various domains including IS (i.e., cognitive absorption theory) and cognitive psychology and human physiology (i.e., resource allocation theory and three $\mathrm{HCI}$ theories). Each of these theories has its own substance yet no studies explored their possible synergies at either epistemological or measurement item levels. We triangulate these theories in order to identify constructs for online wait contexts and explore new theoretical interconnections. Our proposed model goes beyond previous theories in that we (1) develop a specific Web tool, the filler interface, as a means to manipulate PWT, (2) investigate various designs of filler interfaces and their impacts on cognitive absorption dimensions, and (3) consider both antecedents and consequences of PWT for overall Web experience and use.

Fourth, by using a multistudy, multimethod design, this study proposed a theoretical model encompassing the nomological network of interface design, cognitive absorption, PWT, and overall Web site evaluations and use, and empirically validated the model with three lab experiments and structural equation modeling techniques. Our results provide strong support for the theoretical model of online wait as well as practical insights into management of time perceptions during online waits.

Fifth, we confirm the validity of the cognitive absorption construct and investigate its antecedents and consequences.

Agarwal and Karahanna (2000) found that cognitive absorption significantly affected technology use, but they also noted the instability of their measurement items. Through this study, we establish strong theoretical knowledge about cognitive absorption, hence we set a firm basis for further studies in this area. By focusing on system features, we manipulated various filler interface designs and examined how these manipulations differentially affected three dimensions of cognitive absorption. Thus, we validate the significant influence of interface design as a system characteristic on cognitive absorption and suggest opportunities for $\mathrm{HCI}$ researchers to explore the effects of diverse Web interface design components on cognitive absorption dimensions. Furthermore, we expand the applicability of cognitive absorption factors in wait contexts and consider the relationship between cognitive absorption, PWT, and Web site appraisals. Therefore, this study contributes to theoretical advancement of cognitive absorption both in terms of its antecedents (filler interface designs) and consequences (PWT and Web site appraisals).

Finally, by exploring the nomological network of PWT, our proposed model contributes to a better understanding of online user behaviors during waits. We find support for the claim that various filler interface designs manipulate online users' perceptions of time which in turn has important consequences on users' cognitive and affective appraisals and their intentions to use the Web site. While past research investigated individuals' intention to use a Web site, the focus was primarily on perceptions of ease of use, usefulness, and other innovation diffusion factors. This study is among the first to indicate that in an e-business environment, users' perceptions of PWT are a crucial consideration for positive attitude formation (affective appraisals) and Web site use intention. Thus, manipulating PWT through various interface designs can be an effective tool to foster positive affect and intentions. Further, the enjoyment derived from filler interface designs also helps cultivate positive affective evaluations of a Web site.

\section{Practical Implications}

Currently, most filler interfaces on the market appear to be designed largely based on designers' introspection and intuition, leading to irregular patterns and implementation styles. We investigated a wide variety of current practices of using filler interfaces online and found no evidence indicating that rigorous and comprehensive design procedures or guidelines are followed. Generally, few good resources for designing user interfaces (e.g., Apple Computer, Inc. 2008; Shneiderman and Plaisant 2010). These resources that do exist provide rather general discussions and suggestions and most of them are neither specific to filler interface design nor specific to various design elements that could be included on a filler interface. These observations demonstrate the need to design and test various filler interfaces in order to better guide practitioners and derive best practices based on theory. We present a summary in the appendices that includes (1) examples of current (best) practices for wait management (Appendix E), (2) descriptions of waiting screens of 11 commercial travel Web sites (Appendix F), and (3) comparisons of recommendations from best practice, observations of current practice, and implications/guidelines from our findings (Appendix G).

Our experimental findings present useful practical implications for Web designers and Web site managers regarding filler interface designs and their impacts on manipulating customers' PWT. To our knowledge, this is one of the first studies that provide such information to practitioners. First, 
our findings indicate that providing users with a filler interface during wait for an outcome online is significantly more effective than not displaying a filler interface with respect to perceptions of temporal dissociation and focused immersion. This is an important implication for Web interface designers and e-business managers that clearly supports the business case for implementation of a filler interface whenever an unavoidable wait situation occurs online. Thus, an unchanged input screen is clearly inferior and a filler interface has proven capabilities to produce temporal dissociation and focused immersion in users' interaction with the interface, thus altering their PWT.

Second, our findings suggest that with respect to focused immersion displaying either single (text or image) or combinations of visual elements (text and image) on a filler interface works significantly better than using no-filler interface during online waits. However, with respect to temporal dissociation, our results suggest that a combination of design elements (text and image) is superior when compared to the no-filler interface condition and certain single visual cues (e.g., image) but they are equally effective when compared to filler interfaces with text only. Thus, generally, displaying a filler interface with combinations of visual elements (both text and image) is the recommended design strategy for causing temporal dissociation during online waits. This finding provides experimental evidence for e-business managers and/or user interface designers that they should consider a combination of visual cues on their filler interfaces in order to manipulate customers' time perceptions, especially temporal dissociation. However, if confronted with scarce resources, e-business managers and/or designers should consider (at a minimum) textual elements on their filler interfaces in order to create time distortion during online waits.

Third, our findings provide strong evidence for inclusion of task-relevant information on filler interfaces. Relevant visual cues (text and image) on filler interfaces were shown to be significantly more effective than generic visual cues. Filler interfaces with such visual cues successfully manipulated users' perceptions of temporal dissociation, focused immersion, and heightened enjoyment during online waits. Thus, we recommend that Web sites designers use such taskrelevant elements whenever possible on their filler interfaces. One important implication here is also that practitioners should try to understand their users' goals and design filler interfaces around those goals. More specifically, we recommend displaying texts and images relevant to contexts such as travel destinations (e.g., for airfare booking), products and services (e.g., for keyword search), features and functions (e.g., for software installation), special offers and promotions (e.g., for music download), and other wait situations and contexts.
Fourth, our findings suggest that showing moving images on a filler interface is significantly better than using only a static image with regard to temporal dissociation, focused immersion, and heightened enjoyment. Thus, we recommend that in online wait contexts, Web sites or user interface designers should display multiple and dynamically changing images rather than a single, static image. Showing moving images on a filler interface tends to attract more attention from users and increase their heightened enjoyment during the wait.

Finally, the findings regarding significant influences of short PWT time on customers' overall attitude toward the Web site and its use should encourage e-business managers and interface designers to spend more effort and resources on designing effective filler interfaces to manage customers' wait experiences. Filler interfaces should be well-designed to stimulate enjoyment and usefulness perceptions, which in turn correlate with traffic levels and online purchases. By validating the effectiveness of filler interfaces to reduce PWT, this study confirms that filler interfaces are cost-effective solutions to manage online wait over costly technical solutions including software, hardware, or network upgrades.

\section{Conclusion, Limitations, and Future Research Directions}

While our study provides important contributions to both research and practice of online wait management, we acknowledge some limitations as precautions for general interpretation of our results and derived implications.

Our study may lack external validity in the subjects and setting. We used student subjects from a large public university, and conducted controlled lab experiments to control for individual differences in computer system performance and network bandwidth. Although student subjects likely represent the target population of the phenomenon being examined, additional studies with actual customers in real e-business environments are needed to strengthen the generalizability of our findings.

In addition, because we undertook cross-sectional studies, we gathered measures of all study constructs at the same point of time. Therefore, our investigation may suffer potential common method variance biases. Even though our common method variance test reveals no significant bias, further research should adopt study designs that avoid this potential problem, such as longitudinal studies in real e-business environments. 
With a variety of design factors that affect PWT, this study considers only two design components - image and text — and their presentation modes. Although using two design factors is adequate for an initial endeavor into the effect of filler interface designs on online waits, we do recommend that future studies examine the effect of other types of design components used on a filler interface. Examples of design components are a variety of busy, working, and progress indicators, system messages, static and animated cursors, and other animations. In addition, the effect of using different background colors, fonts and marking, various multimedia cues, size and sequence of the presentation cues, and providing wait duration information on a filler interface can be avenues for future investigations into customers' perceptions of PWT online.

As a part of the experiments, the subjects of this study only conducted a single online airline ticket purchase task. Although this task well represents online waits, it will be ideal to replicate this study with different waiting tasks and contexts (e.g., database queries, software download/installation, simulation/model processing, Web e-mail file attachment) to examine the theoretical boundaries of our proposed model.

As an initial inquiry into the effects of filler interfaces and their designs, we did not consider other factors that may affect individuals' online wait perceptions including goals to visit the site (hedonic versus utilitarian), risk propensity (promotion versus prevention focused), wait expectations (high versus low), familiarity with filler interfaces (more versus less), cultural background (monochronic versus polychronic), or task complexity. Researchers should take into account the effect of such factors on online wait perceptions in future research. By doing so, we can gain a better understanding of designing effective filler interfaces that meet users' specific needs in different wait contexts.

In our experiment, we controlled the waiting time as 16 seconds (see footnote 3) based on 100 different travel search scenarios and average wait times of commercial travel sites. Thus, while we believe a 16 -second wait time is adequate (and realistic) in our context of study, we acknowledge that this wait time may be context-dependent. We conjecture that a wait of 16 seconds is relatively long in an online wait situation and can induce online users' cognitive absorption (i.e., focused immersion, temporal dissociation, and heightened enjoyment). Even though our results support most of our hypotheses concerning filler interface designs and online time perceptions, we do caution readers those 16 seconds might not be an appropriate wait time in other online situations.
There may also be a need to investigate different hedonic designs of text, image, image motion, and other features for users' heightened enjoyment during online wait. In addition, future research should also focus on refining the measures for heightened enjoyment (e.g., designing new measurement items beyond those of perceived enjoyment and pleasant/ interesting perceptions).

Finally, efforts that elaborate on the manipulation of filler interfaces with diverse designs also are recommended. For example, other filler interface designs (e.g., multitasking suggestion and progress prediction) for longer waiting scenarios (e.g., software installation, game download, and video/picture upload) can be studied. In addition, as suggested by Shneiderman and Plaisant (2010), besides controlled experiments, other empirical evaluations of filler interface design such as expert reviews, user observations, and acceptance tests can potentially provide richer information to design effective filler interfaces for successfully managing online wait.

In summary, using a multistudy and multimethod approach, we critically examined the effect of filler interfaces on waiting time perceptions and the nomological networks associated with PWT. In this study, we manipulated three filler design conditions according to the presence and relevance of images and text and image motion, and validated their differential contributions to online waiting perceptions. By outlining the antecedents and consequences of PWT, we provided a strong basis for a theoretical model of online waits. Overall, the findings demonstrate strong support for the proposed theoretical model and highlight the importance of usable filler interface designs for managing users' online waiting perceptions, which in turn can trigger positive Web experiences overall.

\section{Acknowledgments}

The authors wish to sincerely thank the senior editor, Dr. Henri Barki, the associate editor, and the anonymous reviewers for their invaluable comments. They have contributed significantly to strengthen this paper. The authors also thank Dr. Jim Courtney whose comments were gratefully appreciated.

\section{References}

Agarwal, R., and Karahanna, E. 2000. "Time Flies When You're Having Fun: Cognitive Absorption and Beliefs about Information Technology Usage," MIS Quarterly (24:4), pp. 665-694.

Anstis, S., Verstraten, A. A. J., and Mather, G. 1998. "The Motion Aftereffect," Trends in Cognitive Science (2), pp. 111-117. 
Antonides, G., Verhoef, P. C., and Van Alast, M. 2002. "Customer Perception and Evaluation of Waiting Time: A Field Experiment," Journal of Customer Psychology (12:3), pp. 193-202.

Appiah, O. 2006. "Rich Media, Poor Media: The Impact of Audio/Video vs. Text/Picture Testimonial Ads on Browsers' Evaluations of Commercial Web Sites and Online Product," Journal of Current Issues and Research in Advertising (28:1), pp. 73-86.

Apple Computer, Inc. 2008. “Apple Human Interface Guidelines,”: Cupertino, CA (http://developer.apple.com/mac/library/ documentation/userexperience/conceptual/applehiguidelines/ XHIGIntro/XHIGIntro.html; accessed June 9, 2008).

Bacon, W. F., and Egeth, H. E. 1994. "Overriding Stimulus-Driven Attentional Capture," Perception \& Psychophysics (55:5), pp. 485-496.

Baker, J., and Cameron, M. 1996. "The Effects of the Service Environment on Affect and Customer Perception of Waiting Time: An Integrative Review and Research Propositions," Journal of the Academy of Marketing Science (24:4), pp. 338-349.

Ball, W., and Tronick, E. 1971. "Infant Responses to Impeding Collision: Optical and Real," Science (171), pp. 818-820.

Barnett, A. I., and Saponaro, A.1985. "Misapplications Reviews: The Parable of the Red Line," Interfaces (15), pp. 33-9.

Baron, R. M., and Kenny, D. A.1986. "The Moderator-Mediator Variable Distinction in Social Psychological Research: Conceptual, Strategic and Statistical Considerations," Journal of Personality and Social Psychology (51), pp. 1173-1182.

Barten, S., Birns, B., and Ronch, J. 1971. "Individual Differences in the Visual Pursuit Behavior of Neonates," Child Development (42), pp. 313-319.

Batra, R., and Ahtola, O. 1991. "Measuring the Hedonic and Utilitarian Sources of Consumer Attitudes," Marketing Letters (2:2). pp. 159-170

Bayles, M. E. 2002. "Designing Online Banner Advertisements: Should We Animate?," in Proceedings of the SIGCHI Conference on Human Factors in Computing Systems: Changing Our World, Changing Ourselves, New York: ACM, pp. 363-366.

Benbasat, I. 2010 "HCI Research: Future Challenges and Directions," AIS Transactions on Human-Computer Interaction (2), pp. 16-21

Block, R. A. 1990. "Models of Psychological Time," in Cognitive Models of Psychological Time, R. A. Block (ed.), Hillsdale, NJ: Erlbaum, pp. 1-35.

Breckler, S. J. 1984. "Empirical Validation of Affect, Behavior, and Cognition as Distinct Components of Attitude," Journal of Personality and Social Psychology (47), pp. 1191-1205.

Burke, M., Hornof, A., Nilsen, E., and Gorman, N. 2005. "HighCost Banner Blindness: Ads Increase Perceived Workload, Hinder Visual Search, and are Forgotten," ACM Transactions on Human-Computer Interaction (12:4), pp. 423-445.

Cameron, M. A., Baker, J., Peterson, M., and Braunsberger, K. 2003. "The Effects of Music, Wait-length Evaluation, and Mood on a Low-Cost Wait Experience," Journal of Business Research (56), pp. 421-430.

Chaiken, S., and Eagly, A. H. 1983. "Communication Modality as a Determinant of Persuasion: The Role of Communicator
Salience," Journal of Personality and Social Psychology (45:2), pp. 241-256.

ChanLin, L. H. 2000. "Attributes of Animation for Learning Scientific Knowledge,” Journal of Instructional Psychology (27), pp. 228-238.

Csikszentmihalyi, M. 1990. Flow, the Psychology of Optimal Experience, New York: Harper Collins.

Davenport, T. H., and Beck, J. C. 2001. The Attention Economy: Understanding the New Currency of Business, Boston, MA: Harvard Business School Press.

Davis, F. D. 1989. "Perceived Usefulness, Perceived Ease of Use, and User Acceptance of Information Technology," MIS Quarterly (13:3), pp. 319-340.

Davis, M. M., and Vollmann, T. E. 1990. "A Framework for Relating Waiting Time and Customer Satisfaction in a Service Operation," The Journal of Services Marketing (4:1), pp. 61-69.

Dellaert, B. G. C., and Kahn, B. E. 1999. "How Tolerable Is Delay? Customers' Evaluation of Internet Web Sites after Waiting," Journal of Interactive Marketing (13:1), pp. 41-54.

Dennis, A. R., and Taylor, N. J. 2006. "Information Foraging on the Web: The Effects of 'Acceptable' Internet Delays on Multi-Page Information Search Behavior," Decision Support Systems (42:2), pp. 810-824.

Detenber, B. H., and Reeves, B. 1996. "A Bio-Informational Theory of Emotion: Motion and Image Size Effects on Viewers," Journal of Communication (46:3), pp. 66-84.

Detenber, B. H., Simons, R. F., and Bennett, G. G. 1998. "Roll'em! The Effects of Picture Motion on Emotional Responses," Journal of Broadcasting and Electronic Media (42), pp. 112-126.

Diao, F., and Sundar, S. S. 2004. "Orienting response and Memory for Web Advertisements," Communication Research (31:5), pp. 537-567.

Dube-Rioux, L., Schmitt, B. H., and Leclerc, F. 1989. “Consumers' Reactions to Waiting: When Delays Affect the Perception of Service Quality," in Advances in Customer Research, T. K. Srull (ed.), Provo, UT: Association of Computer Research, pp. 59-63.

Durrande-Moreau, A. 1999. "Waiting for Service: Ten Years of Empirical Research," International Journal of Service Industry Management (10:2), pp. 171-189.

Eagly, A., and Chaiken, S. 1993. Psychology of Attitudes, Fort Worth, TX: Harcourt Brace Jovanovich.

Fasolo, B., Misuraca, R., McClelland, G. H., and Cardaci, M. 2006. "Animation Attracts: The Attraction Effect in an On-Line Shopping Environment," Psychology \& Marketing (23:10), pp. 799-811.

Fishbein, M., and Ajzen, I. 1975. Belief, Attitude, Intention and Behavior: An Introduction to Theory and Research, Reading, MA: Addison-Wesley.

Folk, C. L., Remington, R. W., and Johnston, J. C. 1992. "Involuntary Covert Orienting is Contingent on Attentional Control Settings," Journal of Experimental Psychology: Human Perception and Performance (18:4), pp. 1030-1044.

Fornell, C., and Larcker, D. 1981. "Structural Equation Models with Unobservable Variables and Measurement Error," Journal of Marketing Research (18:1), pp. 39-50.

Fraisse, P. 1984. "Perception and Estimation of Time," Annual Review of Psychology (35), pp. 1-36. 
Galletta, D., Henry, R., McCoy, S., and Polak, P. 2004. "Web Site Delays: How Tolerant are Users," Journal of the Association for Information Systems (5:1), pp. 1-28.

Galletta, D. F., Henry, R. M., McCoy, S., and Polak., P. 2006. "When the Wait Isn't So Bad: The Interacting Effects of Web site Delay, Familiarity, and Breadth," Information Systems Research (17:1), pp. 20-37.

Girelli, M., and Luck, S. J. 1997. "Are the Same Attentional Mechanisms Used to Detect Visual Search Targets Defined by Color, Orientation, and Motion?," Journal of Cognitive Neuroscience (9:2), pp. 238-253.

Goldstein, E. B. 1989. Sensation and Perception ( ${ }^{\text {rd }}$ ed.), Belmont, CA: Wadsworth Publishing.

Gorn, G. J., Chattopadhyay, A., Tripathi. J., and Sengupta, S. 2004. "Waiting for the Web: How Screen Color Affects Time Perception," Journal of Marketing Research (41), pp. 215-225.

Greenwald, A., and Leavitt, C. 1984. "Audience Involvement in Advertising: Four Level," Journal of Consumer Research (11), pp.581-592.

Guynes, J. L. 1988. "Impact of System Response Time on State Anxiety," Communications of the ACM (31:3), pp. 342-347.

Hair, J., Black, B., Babin, B., Anderson, R., and Tatham, R. 2006. Multivariate Data Analysis ( $6^{\text {th }}$ edition), Upper Saddle River, NJ: Prentice-Hall.

Heo, N. 2006. "Visual Coding of Banner Animation-Two Mechanisms Tested: 'Distinctiveness' and 'Motion Effects,"' in Proceedings of the Annual Meeting of the International Communication Association, Dresden, Germany.

Hillstrom, A. P., and Yantis, S. 1994. "Visual Motion and Attentional Capture," Perception \& Psychophysics (55:4), pp. 399-411.

Hirst, W., and Kalmar, D. 1987. "Characterizing Attentional Resources," Journal of Experimental Psychology: General (116), pp. 63-81.

Hong, W., Thong, J. Y. L., and Tam, K. Y. 2005. "The Effects of Information Format and Shopping Task on Customers' Online Shopping Behavior: A Cognitive Fit Perspective," Journal of Management Information Systems (21:3), pp. 149-184.

Hong, W., Thong, J. Y. L., and Tam, K. Y. 2007. "How Do Web Users Respond to Non-Banner Ads Animation? The Effects of Task Type and User Experience," Journal of the American Society for Information Science and Technology (58:10), pp. 1467-1482.

Hornik, J. 1981. "Time Cue and Time Perception Effect on Response to Mail Surveys," Journal of Marketing Research (18), pp. 243-248.

Hornik, J. 1984. "Subjective and Objective Time Measures: A Note on the Perception of Time in Customer Behavior," Journal of Customer Research (11), pp. 615-618.

Hoxmeier, J. A., and DiCesare, C. 2000. "System Response Time and User Satisfaction: An Experimental Study of Browser-Based Applications," in Proceedings of the $6^{\text {th }}$ Americas Conference on Information Systems, Long Beach, CA.

Hui, M. K., and Tse, A. C. 1996. "What to Tell Customers in Waits of Different Lengths: An Integrative Model of Service Evaluation," Journal of Marketing (60), pp. 81-90.

Janiszewski, C. 1998. "The Influence of Display Characteristics on Visual Exploratory Search Behavior," Journal of Customer Research (25), pp. 290-301.
Jiang, Z., and Benbasat, I. 2005. "Virtual Product Experience: Effects of Visual and Functional Control of Products on Perceived Diagnosticity and Flow in Electronic Shopping," Journal of Management Information Systems (21:3), pp. 111-147.

Jiang, Z., and Benbasat, I. 2007. "The Effects of Presentation Methods and Task Complexity on Online Customers' Product Understanding," MIS Quarterly (31:3), pp. 475-500.

Kahneman, D. 1973. Attention and Effort, Englewood Cliffs, NJ: Prentice-Hall.

Katz, K. L., Larson, B. M., Larson, R. C. 1991. "Prescription for the Waiting-in-Line Blues: Entertain, Enlighten, and Engage," Sloan Management Review (32:2), pp. 44-53.

Kellaris, J. J., and Mantel, S. P. 1994. "The Influence of Mood and Gender on Customers' Time Perceptions," in Advances in Customer Research, Volume 21, C. T. Allen and D. Roedder John (eds.), Provo, UT : Association for Customer Research, pp. 514-518.

Kempf, D. S. 1999. "Attitude Formation from Product Trial: Distinct Roles of Cognition and Affect for Hedonic and Functional Products," Psychology \& Marketing (16:1), pp. 35-50.

Klapp, O. E. 1986. Overload and Boredom: Essays on the Quality of Life in the Information Society, New York: Greenwood Press.

Lai, Y-L., Kuan, K. K. Y., Hui, K-L., and Liu, N. 2009. "The Effects of Moving Animation on Recall, Hedonic and Utilitarian Perceptions, and Attitude," IEEE Transactions on Engineering Management (56:3), pp. 468-477.

Lamy, D., and Tsal, Y. 1999. "A Salient Distractor Does Not Disrupt Conjunction Search," Psychonomic Bulletin and Review (6:1), pp. 93-98.

Lang, A. 1990. "Involuntary Attention and Physiological Arousal Evoked by Structural Features and Emotional Content in TV Commercials," Communication Research (17), pp. 275-299.

Lang, A. 2000. "The Limited Capacity Model of Mediated Message Processing," Journal of Communication (50), pp. 46-67.

LeDoux, J. E. 1995. "Emotion: Clues from The Brain," Annual Review of Psychology (46), pp. 209-35.

Lee, Y., Ellis, M., and Chen, A. 2009. "Designing Preferable Virtual Worlds: An Analogy of Space," in Proceedings of the $15^{\text {th }}$ Americas Conference on Information Systems, San Francisco, CA.

Lee, Y., and Kozar, K. 2009. "Designing Usable Online Stores: A Landscape Preference Perspective," Information and Management (46:1), pp. 31-41.

Mackinlay, J. D., Robertson, G. G., and DeLine, R. 1994. "Developing Calendar Visualizers for the Information Visualizer," in Proceedings of the $7^{\text {th }}$ Annual ACM Symposium on User Interface Software and Technology, Marina del Rey, CA, pp.109-118.

Maister, D. H. 1985. "The Psychology of Waiting Lines," in The Service Encounter, J. Czepiel, M. R. Solomon, and C. F. Surprenant (eds.), Lexington, MA: Lexington Books, pp. 113-123.

Mathwick, C., Wagner, J., and Unni, R. 2010. "ComputerMediated Customization Tendency (CMCT) and the Adaptive e-Service Experience," Journal of Retailing (86), pp. 11-21

McNeil, M. R., Odell, K., and Tseng, C. H. 1991. "Toward the Integration of Resource Allocation into a General Theory of Aphasia," Clinical Aphasiology (21), pp. 21-39. 
Morrison, J., and Vogel, D. 1998. "The Impacts of Presentation Visuals on Persuasion," Information \& Management (33), pp. 125-135.

Nah, F. F. 2004. "A Study of Tolerable Waiting Time: How Long Are Web Users Willing to Wait?," Behaviour \& Information Technology (23:3), pp. 153-163.

Navon, D., and Gopher, D. 1979. "On the Economy of the Human Processing System," Psychological Review (86), pp. 214-255.

Nielsen, J. 2000. Designing Web Usability, Indianapolis, IN: New Riders.

North, A. C., and Hargreaves, D. J. 1996. "Can Music Move People? The Effects of Musical Complexity and Silence on Waiting Time," Environment and Behavior (31:1), pp.136-149.

North, A. C., Hargreaves, D. J., and McKendrick, J. 1999. "Music and On-Hold Waiting Time," British Journal of Psychology (90), pp. 161-164.

Novak, T. P., Hoffman, D. L., and Yung, Y. F. 2000. "Measuring the Customer Experience in Online Environments: A Structural Modeling Approach," Marketing Science (19:1), pp. 22-42.

Ohman, A. 1997. "The Orienting Response, Attention and Learning: An Information Processing Perspective," in The Orienting Reflex in Humans, H. D. Kimmel, E. H. Van Olst and J. F. Orlebecke (eds.), Hillsdale, NJ: Lawrence Erlbaum, pp. 443-471.

Palmer, J. 2002. "Web Site Usability, Design and Performance Metrics," Information Systems Research (13:1), pp. 151-167.

Park, C. W., and Young, S. M. 1986. "Customer Response to Television Commercials: The Impact of Involvement and Background Music on Brand Attitude Formation," Journal of Marketing Research (23:1), pp. 11-24.

Petty, R. E., Cacioppo, J. T., and Schumann, D. 1983. “Central and Peripheral Routes to Advertising Effectiveness: The Moderating Role of Involvement," Journal of Customer Research (10:2), pp. 135-146.

Phillips, B., and Lee, W. N. 2005. "Interactive Animation: Exploring Spokes-Characters on the Internet," Journal of Current Issues and Research in Advertising (27:1), pp. 1-17.

Podsakoff, P. M., MacKenzie, S. B., Lee, J. Y., and Podsakoff, N. P. 2003. "Common Method Biases in Behavioral Research: A Critical Review of the Literature and Recommended Remedies," Journal of Applied Psychology (88), pp. 879-903.

Pruyn, A., and Smidts, A. 1998. "Effects of Waiting on the Satisfaction with the Service: Beyond Objective Time Measures," International Journal of Research in Marketing (15), pp. 321-334.

Rajala, A. K., and Hantula, D. A. 2000. "Towards a Behavioral Ecology of Consumption: Delay-Reduction Effects on Foraging in a Simulated Internet Mall," Managerial and Decision Economics (21:3/4), pp. 145-158.

Ravaja, N. 2004. "Effects of Image Motion on a Small Screen on Emotion, Attention and Memory: Moving-Face Versus StaticFace Newscaster," Journal of Broadcasting and Electronic Media (48:1), pp.108-133.

Reeves, B., and Nass, C. 1996. The Media Equation: How People Treat Computers, Television and New Media Like Real People and Places, New York: Cambridge University Press.
Reeves, B., Lang, A., Kim, E. Y., and Tatar, D. 1999. "The Effects of Screen Size and Message Content on Attention and Arousal," Media Psychology (1), pp. 49-67.

Roca, J. C., Chiu, C-M., and Martinez, F. J. 2006. "Understanding E-Learning Continuance Intention: An Extension of the Technology Acceptance Model," International Journal of HumanComputer Studies (64), pp. 683-696.

Rosbergen, E., Pieters, R., and Wedel, M. 1997. "Visual Attention to Advertising: A Segment-Level Analysis," Journal of Customer Research (24), pp. 305-314.

Rose, G. M., and Straub, D. 2001. "The Effect of Download Time on Customer Attitude toward the E-Service Retailer," e-Service Journal (1:1), pp. 55-76.

Rose, G. M., Meuter, M. L., and Curran, J. M. 2005. "On-Line Waiting: The Role of Download Time and Other Important Predictors on Attitude toward E-Retailers," Psychology \& Marketing (22:2), pp. 127-151.

Rushinek, A., and Rushinek, S. F. 1986. "What Makes Users Happy?," Communications of the ACM (29:7), pp. 594-598.

Rutkowski, A., Saunders, C., Vogel, D., and van Genuchten, M. 2007. "Is It Already 4 a.m. in Your Time Zone? Focus Immersion and Temporal Dissociation in Virtual Teams," Small Group Research (38:1), pp. 98-129

Ryan, G., and Valerde, M. 2006. "Waiting in Line for Online Services: A Qualitative Study of the User's Perspective," Information Systems Journal (16), pp. 181-211.

Saade, R., and Bahli, B. 2005. "The Impact of Cognitive Absorption on Perceived Usefulness and Perceived Ease of Use in On-Line Learning: An Extension of the Technology Acceptance Model," Information \& Management (42), pp. 317-327.

Shin, N. 2006. "Online Learner's Flow Experience: An Empirical Study," British Journal of Educational Technology (37:5), pp. 705-720.

Shneiderman, B., and Plaisant, C. 2010. Designing the User Interface: Strategies for Effective Human-Computer Interaction $\left(5^{\text {th }}\right.$ ed.), Boston, MA: Addison-Wesley.

Simons, R. F., Detenber, B. H., Reiss, J. E., and Shults, C. W. 2000. "Image Motion and Context: A Between- and Within-Subjects Comparison," Psychophysiology (37), pp. 706-710.

Simons, R. F., Detenber, B. H., Roedema, T. M., and Reiss, J. E. 1999. "Emotion Processing in Three Systems: The Medium and the Message," Psychophysiology (36), pp. 619-627.

Skadberg, Y. X., and Kimmel, J. R. 2004. "Visitors' Flow Experience while Browsing a Web Site: Its Measurement, Contributing Factors and Consequences," Computers in Human Behavior (20), pp. 403-422.

Spilman, L. 1999. "From Elements to Perception: Local and Global Processing in Visual Neurons," Perception (28), pp. 1461-1492.

Steinman, R. M., and Levinson, J. Z. 1990. "The Role of Eye Movement in the Detection of Contrast and Spatial Detail," in Eye Movements and Their Role in Visual and Cognitive Processes, E. Kowler (eds.), Amsterdam: Elsevier, pp. 115-160.

Taylor, S. 1994. "Waiting for Service: The Relationship between Delays and Evaluations of Service," Journal of Marketing (58), pp. 56-69. 
Te'eni, D. 2001. "Review: A Cognitive-Affective Model of Organizational Communication for Designing IT," MIS Quarterly (25:2), pp. 251-312.

Tellegen, A. 1982. "Brief Manual for the Differential Personality Questionnaire," unpublished manuscript, University of Minnesota.

Thomas, B. H., and Calder, P. 2001. "Applying Cartoon Animation Techniques to Graphical User Interfaces," ACM Transactions on Human Computer Interaction (8:3), pp.198-222.

Thompson, D. A., Yarnold, P. R., Williams, D. R., and Adams, S. L. 1996. "Effects of Actual Waiting Time, PWT, Information Delivery, and Expressive Quality on Patient Satisfaction in the Emergency Department," Annals of Emergency Medicine (28:6), pp. 657-665.

Todd, S., and Kramer, A. F. 1994. "Attentional Misguidance in Visual Search," Perception \& Psychophysics (56:2), pp. 198-210.

Tom, G., Burns, M., and Zeng, Y. 1997. "Your Life on Hold: The Effect of Telephone Waiting Time on Customer Perception," Journal of Direct Marketing (11:3), pp. 25-31.

Tom, G., and Lucey, S. 1997. "A Field Study Investigating the Effect of Waiting Time on Customer Satisfaction," Journal of Psychology (131), pp. 655-660.

Trafimow, D., and Sheeran, P. 1998. "Some Tests of the Distinction Between Cognitive and Affective Beliefs," Journal of Experimental Social Psychology (34), pp. 378-397.

Trafimow, D., Sheeran, P., Lombardo, B., Finlay, K. A., Brown, J., and Armitage, C. J. 2004. "Affective and Cognitive Control of Persons and Behaviours," British Journal of Social Psychology (43), pp. 207-224.

Van der Heijden, A. H. C. 1992. Selective Attention in Vision, London: Routledge.

Van der Heijden, H. 2002. "On the Cognitive-Affective Structure of Attitudes Toward Information Systems," in Proceedings of the 23rd International Conference on Information Systems, L. Applegate, R. Galliers, and J. I. DeGross (eds.), Barcelona, Spain, pp. 803-806

Van der Heijden, H. 2004. "User Acceptance of Hedonic Information Systems," MIS Quarterly (28:4), pp 695-704.

Venkatesh, V., and Bala, H. 2008. "Technology Acceptance Model 3 and a Research Agenda on Interventions," Decision Sciences (39:2), pp. 273-315.

Venkatesh, V., Speier, C., and Morris, M. G. 2002. "User Acceptance Enablers in Individual Decision-Making about Technology: Toward an Integrated Model," Decision Sciences (33:2), pp. 297-316.

Webster, J., and Ho, H. 1997. "Audience Engagement in Multimedia Presentations," The DATA BASE for Advances in Information Systems (28:2), pp. 63-77.

Weinberg, B. D. 2000. "Don't Keep Your Internet Customers Waiting Too Long At the (Virtual) Front Door," Journal of Interactive Marketing (14:1), pp. 30-39.

Wolfinbarger, M., and Gilly, M. C. 2003. "eTailQ: Dimensionalizing, Measuring and Predicting eTail Quality," Journal of Retailing (79), pp. 183-198.

Woodside, A. G., and Clokey, J. D. 1974. "Multi-Attributes/MultiBrand Models," Journal of Advertising Research (14), pp. 33-52.
Yantis, S., and Egeth, H. E. 1999. "On the Distinction Between Visual Salience and Stimulus-Driven Attentional Capture," Journal of Experimental Psychology: Human Perception and Performance (25:3), pp. 661-676.

Yantis, S., and Jonides, J. 1984. "Abrupt Visual Onsets and Selective Attention: Evidence from Visual Search," Journal of Experimental Psychology: Human Perception and Performance (10), pp. 601-621.

Yoo, C., Park, J., and MacInnis, D. J. 1998. "Effects of Store Characteristics and in-Store Emotional Experiences on Store Attitude," Journal of Business Research (42:3), pp. 253-263.

Zajonc, R. B. 1980. "Feelings and Thinking: Preferences Need No Inferences," American Psychologist (35:2), pp. 151-175

Zakay, D. 1989. "Subjective Time and Attentional Resource Allocation: An Integrated Model of Time Estimation," in Time and Human Cognition: A Life Span Perspective, I. Levin and D. Zakay (eds.), Amsterdam: Elsevier Science, pp. 365-397.

Zakay, D., and Block, R. A. 2004. "Prospective and Retrospective Duration Judgments: An Executive-control Perspective," Acta Neurobiologiae Experimentalis (64), pp. 319-328.

Zakay, D., and Hornik, J. 1991. "How Much Time Did You Wait in Line? A Time Perception Perspective," in Time and Customer Behavior, J-C. Chebat and V. Venkatesan (eds.), Montreal: Universite du Quebec a Montreal.

Zettl, H. 1973. Sight, Sound, Motion: Applied Media Aesthetics ( $3^{\text {rd }}$ ed.), Belmont, CA: Wadsworth.

Zhang, P. 2000. "The Effects of Animation on Information Seeking Performance on the World Wide Web: Securing Attention or Interfering with Primary Tasks?," Journal of the Association for Information Systems (59:4), pp. 397-402.

Zviran, M., Te'eni, D., and Gross, Y. 2006. "Does Color in E-Mail Make a Difference?" Communications of the ACM (49:4), pp. 94-99.

\section{About the Authors}

Younghwa Lee is an associate professor in the College of Business Administration, University of Northern Iowa. He received his Ph.D. from the University of Colorado at Boulder in 2005. His research interests are in the areas of technology acceptance, website usability, and IT ethics and security. Younghwa is a 2003 ICIS Doctoral Consortium fellow. He has published in Communications of the ACM, Decision Support Systems, Information \& Management, Journal of Management Information Systems, and Journal of Organizational Computing and Electronic Commerce, among others.

Andrew Chen is an associate professor of information systems at the School of Business at the University of Kansas. His current teaching and research interests include knowledge management, IT business value, computer interface design, database management, and business and Web programming applications. His research work appears in Decision Sciences, Decision Support Systems, European Journal of Operational Research, Journal of Electronic Commerce Research, Journal of Management Information Systems, and MIS Quarterly. 
Virginia Ilie is an assistant professor in the School of Management at California Lutheran University. She holds a Ph.D. in Information Systems from the University of Central Florida. Currently, her research interests are in the area of information technology implementation in healthcare organizations, including individual acceptance of clinical information systems. Her work has appeared in journals such as Decision Sciences, European Journal of Information Systems, Database, and International Journal of Health Information Systems and Informatics. She received the best paper awards from the Americas Conference in Information Systems and the International Conference on Information Systems. 


\title{
Can Online Wait Be Managed? The Effect of FILLER INTERFACES AND PRESENTATION MODES On Perceived Waiting TIME ONLINE
}

\author{
Younghwa Lee \\ Department of Management, College of Business Administration, University of Northern lowa, \\ Cedar Falls, IA 50614 U.S.A. \{gabe.lee@uni.edu\} \\ Andrew N. K. Chen \\ Accounting and Information Systems, School of Business, University of Kansas, 1300 Sunnyside Avenue, \\ Lawrence, KS 66045 U.S.A. \{achen@ku.edu\} \\ Virginia Ilie \\ School of Management, California Luthern University, 60 West Olsen Road, \\ Thousand Oaks, CA 91360 U.S.A. \{ilie.virginia@gmail.com\}
}




\section{Appendix A}

Input Screens, Filler Interfaces, and Output Screens for the Simulated Online Travel System
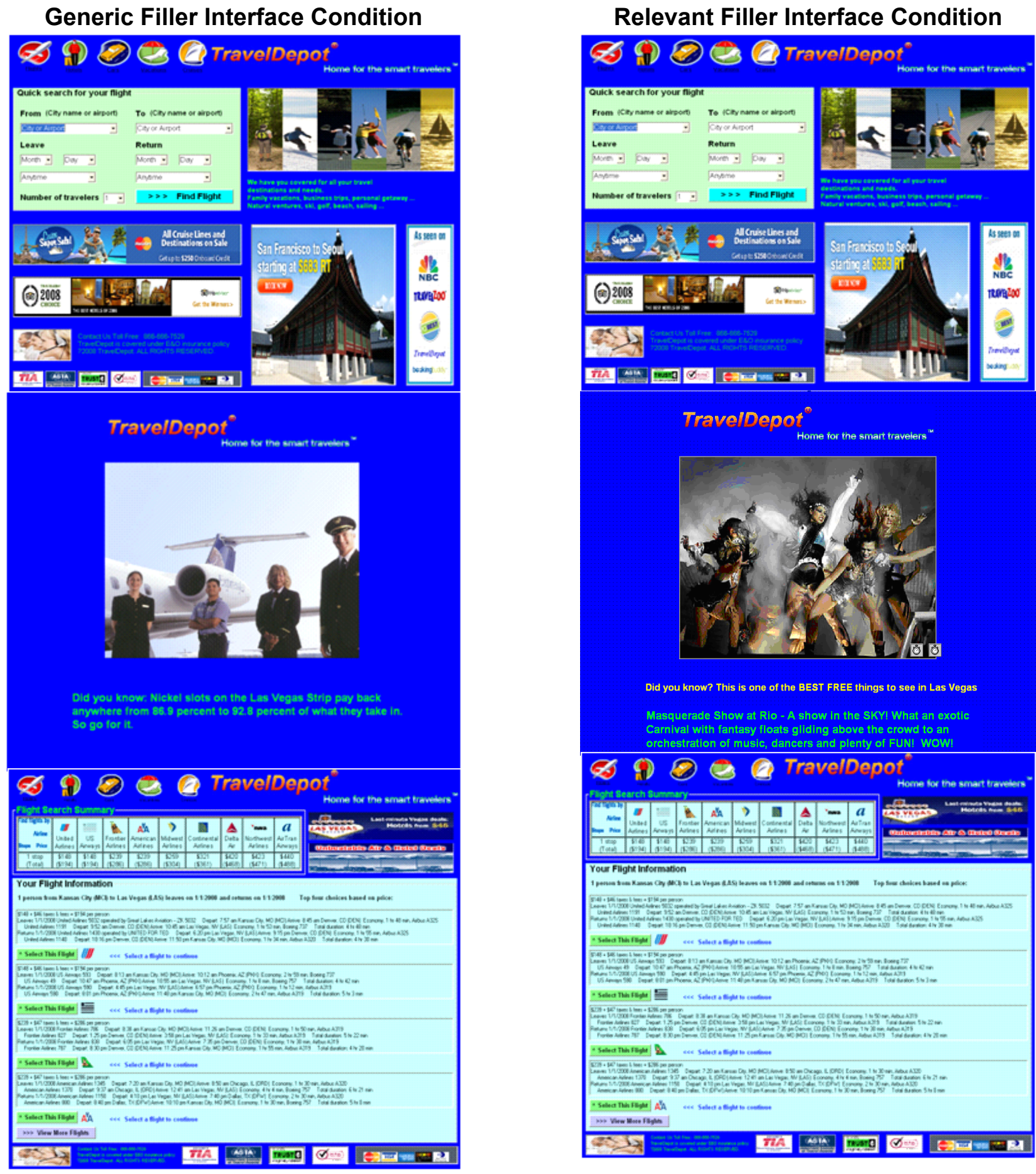

Did you know? This is one of the BEST FREE things to see in Las Vegas

Masquerade Show at Rio - A show in the SKY! What an exotic Carnival with fantasy floats gliding above the crowd to an orchestration of music, dancers and plenty of FUN! WOW!

\& D O O TravelDepot"

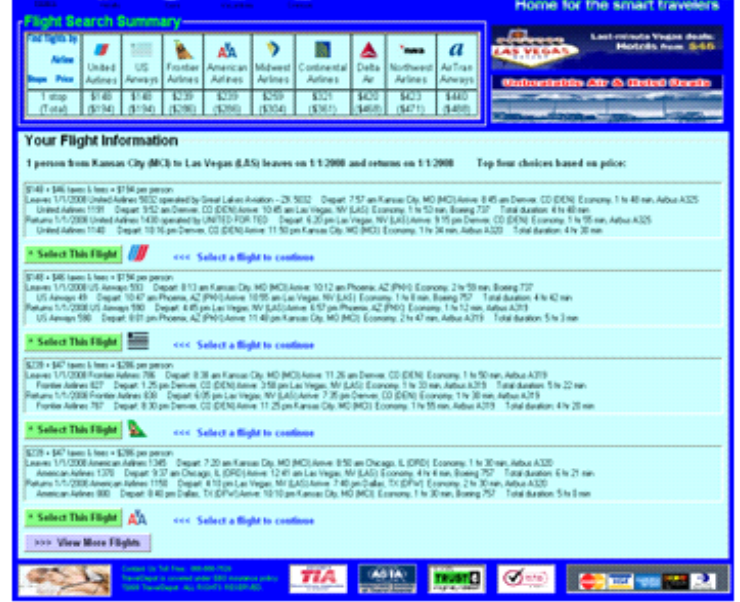




\section{Appendix B}

\section{Instrument Items}

\begin{tabular}{|c|c|c|}
\hline Construct & Items & Description \\
\hline \multirow{4}{*}{$\begin{array}{l}\text { Focused } \\
\text { Immersion* }\end{array}$} & $\mathrm{FI1}$ & I was intensely absorbed in a filler interface while waiting to see the results. \\
\hline & $\mathrm{FI} 2$ & My attention was focused on a filler interface while I was waiting to see the results. \\
\hline & $\mathrm{FI3}$ & I concentrated fully on a filler interface while waiting to see the results. \\
\hline & FI4 & I was deeply immersed in a filler interface while waiting to see the results. \\
\hline \multirow{5}{*}{$\begin{array}{l}\text { Temporal } \\
\text { Dissociation }\end{array}$} & TD1 & Time appeared to go by very quickly while waiting to see the results. \\
\hline & TD2 & I lost track of time while waiting to see the results. \\
\hline & TD3 & I was unconscious of the passage of time while waiting to see the results. \\
\hline & $\overline{T D 4}$ & Time seemed to fly while I was waiting to see the results. \\
\hline & TD5 & While waiting to see the results, I forgot the passage of time \\
\hline \multirow{4}{*}{$\begin{array}{l}\text { Heightened } \\
\text { Enjoyment }\end{array}$} & HE1 & $\begin{array}{l}\text { Waiting for the requested results in the filler interface was: } \\
\text { Pleasant }\end{array}$ \\
\hline & HE2 & Enjoyable \\
\hline & HE3 & Fun \\
\hline & HE4 & Exciting \\
\hline \multirow{3}{*}{ PWT } & PWT1 & Your online wait to see the requested results was: Fast \\
\hline & PWT2 & Speedy \\
\hline & PWT3 & Quick \\
\hline \multirow{5}{*}{$\begin{array}{l}\text { Affective } \\
\text { Appraisal }\end{array}$} & AA1 & $\begin{array}{l}\text { My overall experience with the Web site was: } \\
\text { Happy }\end{array}$ \\
\hline & AA2 & Good \\
\hline & AA3 & Relaxed \\
\hline & AA4 & Likable \\
\hline & AA5 & Satisfactory \\
\hline \multirow{4}{*}{$\begin{array}{l}\text { Cognitive } \\
\text { Appraisal }\end{array}$} & CA1 & The Web site was effective for achieving the goal of my visit. \\
\hline & CA2 & The Web site was convenient for attaining the goal of my visit. \\
\hline & CA3 & I felt comfortable using the Web site to achieve the goal of my visit. \\
\hline & CA4 & The Web site was helpful for achieving the goal of my visit. \\
\hline \multirow{3}{*}{ Use Intention } & UI1 & If I needed this service in the future, I would probably revisit this Web site. \\
\hline & $\mathrm{UI} 2$ & I would recommend this Web site to others who are interested in this service \\
\hline & $\mathrm{UI} 3$ & If I needed this service in the future, I would probably try this Web site again. \\
\hline \multirow{5}{*}{$\begin{array}{l}\text { Perceived } \\
\text { Relevance }^{\star *}\end{array}$} & PR1 & Image/text provided in a filler interface was informative to me. \\
\hline & PR2 & Image/text provided in a filler interface was valuable to me. \\
\hline & PR3 & Image/text provided in a filler interface did matter to me. \\
\hline & PR4 & Image/text provided in a filler interface was helpful to me. \\
\hline & PR5 & Image/text provided in a filler interface was useful to me \\
\hline \multirow{2}{*}{$\begin{array}{l}\text { Perceived } \\
\text { Image Motion }\end{array}$} & $\mathrm{IM} 1$ & I feel that the image showing in a filler interface is in motion. \\
\hline & IM2 & I feel that the image showing in a filler interface is moving. \\
\hline
\end{tabular}

Note: $\quad$ Seven-point Likert-type scales were used to measure the items above $(1=$ strongly disagree to $7=$ strongly agree $)$ except for perceived relevance, which uses five-point scales.

*In the no-filler interface condition, subjects did not see a filler interface and thus we could not directly use the same items to measure "focused immersion on the filler interface." Instead, we used items to measure "focused immersion on waiting" (e.g., I was intensely absorbed in the waiting while waiting to see the results). After gathering the data, we reverse coded the items for the no-filler interface condition before conducting our ANOVA tests. The derived scores for both the no-filler and the filler interface conditions represented the degree of distracted attention from waiting itself.

${ }^{* *}$ For pretests of perceived relevance and image motion, we did not include the wording "in a filler interface" in items. 


\section{Appendix C}

\section{Pretests for Study 3}

\section{Independent Variables}

In order to develop the treatment conditions for the relevance of text and images, we first recruited 15 subjects who had at least 1 year of usage experience with travel Web sites and had visited the destination city (Las Vegas) at least once. After explaining the purpose of our study, we asked them to identify three highly relevant texts/images and three generic (i.e., low relevant) texts/images pertaining to the search outcome (e.g., Las Vegas). The operational definition of relevance is rooted in visual search theory, the extent to which filler design components (e.g., text or image) are perceived as being pertinent to the search tasks. After sorting and regrouping their inputs, we identified 13 texts and 17 images. Four doctoral students examined these results and selected two highly relevant texts (e.g., "Masquerade Show at Rio - A Show in the SKY! What an exotic Carnival with fantasy floats gliding above the crowd to an orchestration of music, dancers and plenty of FUN!"), two generic texts (e.g., "TravelDepot always strives to offer the best price and flight selection for customers like you. Please wait while we are searching for your flights. Thank you very much."), five high relevant images, ${ }^{1}$ and five generic images. The same 15 subjects then evaluated the relevance of these selected text passages and images on five relevance scales (McKinney et al. 2002). That is, each subject evaluated the relevance-level of each image/text by using items such as "Information (images) provided in the filler interface was informative to me" (Cronbach's $\alpha=.872$ ). According to the relevance rankings of the images and text, we derived one highly relevant text, one generic text, five highly relevant images, and five generic images. As we show in Table C1, our subjects noted significant differences on their perceived relevance between relevant and generic images and text.

Based on motion effect theory, image motion was operationalized as a rapidly changing image slideshow representing the illusion of movement (ChanLin 2000). Images were classified into two experimental conditions: moving and static. We fixed the waiting time to 16 seconds (see footnote 3 in the paper) and created five different filler interfaces. For example, in the one-image-in-sixteen-seconds condition (static image), only one image appeared during the 16-second wait period. In the five-images-in-sixteen-seconds condition, five different images appeared sequentially during the 16-second wait period. The five highly relevant images identified earlier by these subjects were used in these interface designs. The same 15 subjects assessed image motion for each one of these five filler interface conditions using two perceived image motion items (e.g., "I feel that the image showing in a filler interface is in motion") (Cronbach's $\alpha=.754$ ). The results of the ANOVA test indicated that subjects perceived significant differences in image motion across the five screen manipulations. A post hoc test (see Table C2) also indicated significant differences between all conditions, except between the four images in 16 seconds and 5 images in 16 seconds condition (Tukey HSD: mean difference $=-.05, \mathrm{SE}=.17, \mathrm{p}>.05$ ). We also performed another ANOVA test with less relevant images and found the same results. From these results, we selected the one-image-in-sixteen-seconds condition as the static condition and the four-images-in-sixteenseconds condition as the motion condition to test the effect of image motion on online wait perceptions.

Table C1. Pretest of Study 3: Descriptive Statistics of "Perceived Relevance" for Relevant Versus Generic Images and Text Conditions

\begin{tabular}{|c|c|c|c|c|c|c|c|}
\hline & Relevance & Description & Mean & S.D. & F-test & DF & Sig. \\
\hline \multirow[t]{2}{*}{ Text } & Relevant & $\begin{array}{l}\text { Las Vegas hotel \& famous show } \\
\text { information }\end{array}$ & 5.57 & 0.503 & \multirow[t]{2}{*}{333.057} & \multirow[t]{2}{*}{$(1,28)$} & \multirow[t]{2}{*}{$P<0.001$} \\
\hline & Generic & Travel site motto & 3.42 & 0.402 & & & \\
\hline \multirow[t]{2}{*}{ Image } & Relevant & $\begin{array}{l}\text { Main strip hotels and recent shows } \\
\text { in Las Vegas }\end{array}$ & 5.22 & 0.600 & \multirow[t]{2}{*}{1140.837} & \multirow[t]{2}{*}{$(1,148)$} & \multirow[t]{2}{*}{$P<0.001$} \\
\hline & Generic & Flight attendance, meal, cabin & 2.44 & 0.405 & & & \\
\hline
\end{tabular}

*Five perceived relevance items were used to calculate mean and standard deviation. A seven-point Likert-type scale was used to measure the items $(1$ = Strongly disagree... 7 = strongly agree $)$

\footnotetext{
${ }^{1}$ We need five high and low relevant images to design filler interfaces and investigate the effect of static versus moving images.
} 
Table C2. Pretest of Study 3: Descriptive Statistics and Comparisons of "Perceived Image Motion" for alternatives of Image Motion

\begin{tabular}{|c|c|c|c|}
\hline Filler Interface & (J) Filler Interface & Mean Difference $(\mathrm{I}-\mathrm{J})$ & Sig. \\
\hline \multirow{4}{*}{$\begin{array}{l}1(\text { Mean }=1.800, S D=.455) \\
\text { One image was shown during } 16 \text { seconds }\end{array}$} & $2($ Mean $=3.125)$ & -1.325 & .000 \\
\hline & $3($ Mean $=4.143)$ & -2.343 & .000 \\
\hline & $4($ Mean $=5.033)$ & -3.233 & .000 \\
\hline & $5($ Mean $=4.800)$ & -3.000 & .000 \\
\hline \multirow{4}{*}{$\begin{array}{l}2(\text { Mean }=3.125, \mathrm{SD}=.341) \\
\text { Two images in sixteen seconds } \\
\text { Image changes every } 8 \text { seconds }\end{array}$} & $1($ Mean $=1.800)$ & 1.325 & .000 \\
\hline & $3($ Mean $=4.143)$ & -1.018 & .000 \\
\hline & $4($ Mean $=5.033)$ & -1.908 & .000 \\
\hline & $5($ Mean $=4.800)$ & -1.675 & .000 \\
\hline \multirow{4}{*}{$\begin{array}{l}3(\text { Mean }=4.143, S D=.663) \\
\text { Three images in sixteen seconds } \\
\text { Image changes every } 5.3 \text { seconds }\end{array}$} & $1($ Mean $=1.800)$ & 2.343 & .000 \\
\hline & $2($ Mean $=3.125)$ & 1.018 & .000 \\
\hline & $4($ Mean $=5.033)$ & -0.890 & .001 \\
\hline & $5($ Mean $=4.800)$ & -0.657 & .003 \\
\hline \multirow{4}{*}{$\begin{array}{l}4(\text { Mean }=5.033, S D=.611) \\
\text { Four images in sixteen seconds Image } \\
\text { changes every } 4 \text { seconds }\end{array}$} & $1($ Mean $=1.800)$ & 3.233 & .000 \\
\hline & $2($ Mean $=3.125)$ & 1.908 & .000 \\
\hline & $3($ Mean $=4.143)$ & 0.890 & .001 \\
\hline & $5($ Mean $=4.800)$ & 0.233 & .999 \\
\hline \multirow{4}{*}{$\begin{array}{l}5(\text { Mean }=4.800, S D=.592) \\
\text { Five images in sixteen seconds } \\
\text { Image changes every } 3.2 \text { seconds }\end{array}$} & $1($ Mean $=1.800)$ & 3.000 & .000 \\
\hline & $2($ Mean $=3.125)$ & 1.675 & .000 \\
\hline & $3($ Mean $=4.143)$ & 0.657 & .003 \\
\hline & $4($ Mean $=5.033)$ & -0.233 & .999 \\
\hline
\end{tabular}

*Two perceived image motion items were used to calculate mean and standard deviation. A seven-point Likert-type scale was used to measure the items $(1=$ Strongly disagree, $7=$ strongly agree $)$

\section{Dependent Variables}

We used the same measures from Study 1 to assess temporal dissociation and focused immersion, and included yet another variable, heightened enjoyment. As discussed in the hypotheses section, in addition to focused immersion and temporal dissociation, users may also perceive enjoyment when they see interface design objects that provide informational and visual support for completing their tasks or moving objects (Hong et al. 2005). Heightened enjoyment was measured using four items from Agarwal and Karahanna (2000) (see Appendix C). An exploratory study with 38 business school students who have used online travel sites was conducted for these dependent variables. All measures showed appropriate levels of convergent and discriminant validity (Eigenvalue for the three constructs were all greater than 1; all factor loading scores were greater than 0.728 ; and each item grouped well with its own construct). Cronbach's alpha values were all greater than 0.929 indicating appropriate reliability.

\section{References}

Agarwal, R., and Karahanna, E. 2000. "Time Flies When You're Having Fun; Cognitive Absorption and Beliefs about Information Technology Usage,” MIS Quarterly (24:4), pp. 665-694.

ChanLin, L. H. 2000. “Attributes of Animation for Learning Scientific Knowledge,” Journal of Instructional Psychology (27), pp. $228-238$. Hong, W., Thong, J. Y. L., and Tam, K. Y. 2005. “The Effects of Information Format and Shopping Task on Customers' Online Shopping Behavior: A Cognitive Fit Perspective," Journal of Management Information Systems (21:3), pp. 149-184.

McKinney, V., Yoon, K., and Zahedi, F. M. 2002. "The Measurement of Web-Customer Satisfaction: An Expectation and Disconfirmation Approach," Information Systems Research (13:3), pp. 296-315. 


\section{Appendix D}

Path Coefficient and Model Fit Comparisons

\begin{tabular}{|c|c|c|c|c|c|c|c|}
\hline DV & & IV & AA-PWT & CA-PWT & AA-UI & CA-UI & PWT-UI \\
\hline PWT & $\leftarrow$ & TD & -.125 & -.099 & -.126 & -.125 & -.123 \\
\hline PWT & $\leftarrow$ & $\mathrm{HE}$ & -.374 & -.347 & -.374 & -.374 & -.372 \\
\hline PWT & $\leftarrow$ & $\mathrm{FI}$ & -.388 & -.442 & -.388 & -.388 & -.385 \\
\hline AA & $\leftarrow$ & PWT & -.385 & -.351 & -.389 & -.372 & -.370 \\
\hline AA & $\leftarrow$ & $\mathrm{HE}$ & .401 & .432 & .423 & .417 & .420 \\
\hline CA & $\leftarrow$ & PWT & -.453 & -.440 & -.434 & -.436 & -.446 \\
\hline CA & $\leftarrow$ & AA & .320 & .343 & .356 & .345 & .333 \\
\hline CA & $\leftarrow$ & $\mathrm{HE}$ & -.049 & -.057 & -.070 & -.081 & -.055 \\
\hline UI & $\leftarrow$ & CA & .369 & .369 & .335 & .392 & .963 \\
\hline UI & $\leftarrow$ & AA & .385 & .387 & .819 & .646 & .892 \\
\hline
\end{tabular}

*Bold represents significant path coefficients at $p<0.05$.

\section{Table D2. Model Fit Comparison}

\begin{tabular}{|l|c|c|c|c|c|c|c|c|c|}
\hline \multicolumn{1}{|c|}{ Model } & CMIN & DF & P & CMIN/DF & GFI & AGFI & NFI & CFI & RMSEA \\
\hline AA-PWT & 771.940 & 323 & .000 & 2.390 & .861 & .826 & .938 & .963 & .063 \\
\hline CA-PWT & 745.083 & 324 & .000 & 2.300 & .864 & .830 & .940 & .965 & .061 \\
\hline AA-UI & 730.576 & 323 & .000 & 2.262 & .867 & .832 & .941 & .966 & .060 \\
\hline CA-UI & 737.470 & 324 & .000 & 2.276 & .866 & .832 & .941 & .966 & .060 \\
\hline PWT-UI & 745.394 & 325 & .000 & 2.294 & .864 & .830 & .940 & .965 & .060 \\
\hline
\end{tabular}




\section{Appendix E}

\section{Summary of Practices for Wait Management}

\begin{tabular}{|c|c|c|}
\hline Context & Best Practices & Source \\
\hline $\begin{array}{l}\text { Wait } \\
\text { online }\end{array}$ & $\begin{array}{l}\text { A macro will perform a Wait for Web Page in Netscape } 7.1 \text { by watching an area on the browser's } \\
\text { window that changes color when a Web page is loading and then wait for that color to return to } \\
\text { normal. }\end{array}$ & Netscape \\
\hline $\begin{array}{l}\text { Wait } \\
\text { page }\end{array}$ & $\begin{array}{l}\text { A few articles mention about a simple "Please Wait ..." page or how to program a component } \\
\text { (e.g., a progress bar) to show the percentage of completion or progress of the page loading. }\end{array}$ & $\begin{array}{l}\text { MSDN (Microsoft } \\
\text { Development Network) }\end{array}$ \\
\hline $\begin{array}{l}\text { Wait } \\
\text { page }\end{array}$ & Show a simple wait message on a wait page. & $\begin{array}{l}\text { ASP.NET WaitPage } \\
\text { Framework }\end{array}$ \\
\hline $\begin{array}{l}\text { Wait } \\
\text { message }\end{array}$ & $\begin{array}{l}\text { Selected content such as product information and announcements is provided during waiting time } \\
\text { of an Internet session. In one implementation, the process implemented by the waiting time } \\
\text { message program of the invention involves monitoring a user node to identify a web site access } \\
\text { request, accessing a previously stored message set, selecting a message from the message set } \\
\text { and displaying or playing back the selected message. The message set and particular messages } \\
\text { may be selected based on user information (e.g., demographic, psychographic, or product } \\
\text { preference information), information regarding the expected waiting time or other information. } \\
\text { Messages are thereby provided during waiting time that would otherwise be essentially wasted } \\
\text { from the perspective of an ordinary Internet user. }\end{array}$ & $\begin{array}{l}\text { US Patent 5,996,007 - } \\
\text { Method for Providing } \\
\text { Selected Content during } \\
\text { Waiting Time of an } \\
\text { Internet Session }\end{array}$ \\
\hline $\begin{array}{l}\text { Wait } \\
\text { display }\end{array}$ & $\begin{array}{l}\text { In a method of displaying advertising and communicating computer operation during a wait } \\
\text { period, a plurality of images is displayed during the wait period in a predetermined sequence as } \\
\text { part of an animation that indicates that the wait period is proceeding. Advertising information is } \\
\text { integrated with the plurality of images. }\end{array}$ & $\begin{array}{l}\text { US Patent } 6,304,852- \\
\text { Method of Commu- } \\
\text { nicating Computer } \\
\text { Operation during a Wait } \\
\text { Period }\end{array}$ \\
\hline $\begin{array}{l}\text { Wait } \\
\text { display }\end{array}$ & Traffic light countdown, crosswalk countdown, crosswalk animation & $\begin{array}{l}\text { Multiple cities in multiple } \\
\text { countries }\end{array}$ \\
\hline $\begin{array}{l}\text { Wait } \\
\text { display }\end{array}$ & $\begin{array}{l}\text { It keeps the user informed during the upload process. While uploading files the user is kept in the } \\
\text { know with several indicators, from the percentage of the file that has been uploaded to the factors } \\
\text { that may dictate the speed of the upload. Even though the user is waiting, a feeling of } \\
\text { accomplishment can be felt when the file upload is in the process of completion. }\end{array}$ & VirusTotal Web site \\
\hline $\begin{array}{l}\text { Wait } \\
\text { display }\end{array}$ & $\begin{array}{l}\text { They present how much time is left before the advertisement is over - reducing frustration } \\
\text { produced by waiting for ads and giving the user an understanding of the time frame left before } \\
\text { they can see what they came for. }\end{array}$ & $\begin{array}{l}\text { Hulu Web site, ESPN } \\
\text { Web site }\end{array}$ \\
\hline $\begin{array}{l}\text { Wait } \\
\text { page }\end{array}$ & $\begin{array}{l}\text { When users upload videos and photos to their Facebook, they are given a status window in a } \\
\text { new window. This status window shows an image caption which shows which photo or video is } \\
\text { currently being uploaded. As the thumbnails of your images flicker before your eyes you see } \\
\text { progress being made. In addition there is a text notification section which tells your user what is } \\
\text { going on. This text information allows the user to understand the process and see progress be } \\
\text { made as well. Finally, there is a status bar. Just was we see when loading other applications this } \\
\text { bar moves farther to the left the closer we are to being done. All of the indicators provided by } \\
\text { Facebook are developed to inform users what is going on during their wait to help provide a } \\
\text { better user experience. }\end{array}$ & Facebook \\
\hline $\begin{array}{l}\text { Wait } \\
\text { page }\end{array}$ & $\begin{array}{l}\text { Discuss how to use busy indicator, working indicator, system messages, progress indicator, static } \\
\text { wait cursors, animated cursors, and wait animations at three different wait situations (levels, } \\
\text { lengths) - perceptual, dialog, and cognitive. }\end{array}$ & $\begin{array}{l}\text { SAP Design Guide - } \\
\text { Waiting at the Computer: } \\
\text { Busy Indicators and } \\
\text { System Feedback }\end{array}$ \\
\hline $\begin{array}{l}\text { Wait } \\
\text { design }\end{array}$ & $\begin{array}{l}\text { Provide information on screens to create a more relaxing and inviting environment which will } \\
\text { decrease perceived wait times. } \\
\text { Show helpful reminders, facility news, and industry information to keep your audience entertained } \\
\text { and informed while they wait. } \\
\text { Decrease the perceived wait times of your clients by highlighting your products and services } \\
\text { while they wait. } \\
\text { Show specials, seasonal information, or helpful reminders that keep your communication up-to- } \\
\text { date, helpful, and relevant to the audience. }\end{array}$ & $\begin{array}{l}\text { RoninCast - Wireless } \\
\text { Ronin Technologies }\end{array}$ \\
\hline $\begin{array}{l}\text { Wait } \\
\text { design }\end{array}$ & $\begin{array}{l}\text { CastOven and HappyPrinter are two examples that exploiting waiting time. They use video, light, } \\
\text { and background music to make waiting time to entertain and augment the experience. }\end{array}$ & $\begin{array}{l}\text { CastOven and } \\
\text { HappyPrinter }\end{array}$ \\
\hline
\end{tabular}




\section{Appendix F}

\section{Summary and Descriptions of Waiting Screens}

\section{Table F1. Summary of Waiting Screens of Eleven Travel Sites}

\begin{tabular}{|c|c|c|c|c|c|c|}
\hline Site & $\begin{array}{c}\text { Background } \\
\text { Color }\end{array}$ & Logo & Image & Text & Image Motion & Position \\
\hline $\begin{array}{l}11 \text { travel booking } \\
\text { sites }\end{array}$ & $\begin{array}{l}\text { Blue }-6 \\
\text { White }-2 \\
\text { Red - } 1 \\
\text { Grey - } 1 \\
\text { Green - } 1\end{array}$ & $\begin{array}{l}\text { Yes }-11 \\
\text { (small and } \\
\text { medium } \\
\text { size) }\end{array}$ & $\begin{array}{l}\text { Yes }-6 \text { (all } \\
\text { irrelevant) } \\
\text { No }-5\end{array}$ & $\begin{array}{l}\text { Yes - } 11 \text { (all } \\
\text { irrelevant) }\end{array}$ & $\begin{array}{l}\text { Yes }-10 \text { (different } \\
\text { varieties) } \\
\text { No }-1\end{array}$ & $\begin{array}{l}\text { Middle and top- } \\
\text { middle }-9 \\
\text { Whole page }-1 \\
\text { Top-left - } 1\end{array}$ \\
\hline
\end{tabular}

\section{Table F2. Descriptions of Waiting Screens of Eleven Travel Sites}

\begin{tabular}{|c|c|c|c|c|c|c|}
\hline Site & $\begin{array}{c}\text { Background } \\
\text { Color }\end{array}$ & Logo & Image & Text & Image Motion & Position \\
\hline cheapOair.com & White & $\begin{array}{l}\text { Yes (medium } \\
\text { size) }\end{array}$ & No & $\begin{array}{l}\text { Irrelevant (flight } \\
\text { information, } \\
\text { about flight } \\
\text { database) }\end{array}$ & $\begin{array}{l}\text { Traditional } \\
\text { progress bar }\end{array}$ & $\begin{array}{l}\text { In the middle }(1 / 3 \\
\text { size) }\end{array}$ \\
\hline $\begin{array}{l}\text { CheapTickets.co } \\
\text { m }\end{array}$ & Red & Yes (small) & $\begin{array}{l}\text { Yes (irrelevant)/ } \\
\text { No (a large } \\
\text { circle with "No } \\
\text { Booking Fee") }\end{array}$ & $\begin{array}{l}\text { Irrelevant } \\
\text { (slogan) }\end{array}$ & $\begin{array}{l}\text { Animated circles } \\
\text { moving across as } \\
\text { the progress bar }\end{array}$ & Top middle ( $1 / 3$ size) \\
\hline SmartFares.com & Dodger Blue & Yes (small) & $\begin{array}{l}\text { Yes(irrelevant)/ } \\
\text { No (banner ad) }\end{array}$ & $\begin{array}{l}\text { Irrelevant (flight } \\
\text { information, } \\
\text { dare to } \\
\text { compare, } \\
\text { banner ad) }\end{array}$ & $\begin{array}{l}\text { Blinking dots } \\
\text { inside a shape of a } \\
\text { rectangle }\end{array}$ & Top middle (1/4 size) \\
\hline Hotwire.com & Grey & $\begin{array}{l}\text { Yes (in the } \\
\text { shaded } \\
\text { background) }\end{array}$ & $\begin{array}{l}\text { Yes(irrelevant) } \\
\text { (in the shaded } \\
\text { background) }\end{array}$ & $\begin{array}{l}\text { Irrelevant (flight } \\
\text { information/in } \\
\text { the shaded } \\
\text { background) } \\
\text { (Updating ...) }\end{array}$ & $\begin{array}{l}\text { Icon-changing } \\
\text { (bed, flight, cruise) } \\
\text { and dot-moving } \\
\text { (after the word } \\
\text { "Updating") }\end{array}$ & $\begin{array}{l}\text { In the middle (very } \\
\text { small) }\end{array}$ \\
\hline CheapAir.com & Royal Blue & Yes (small) & No & $\begin{array}{l}\text { Irrelevant } \\
\text { (please wait, } \\
\text { etc.) }\end{array}$ & $\begin{array}{l}\text { Diamonds change } \\
\text { colors across as } \\
\text { the progress bar } \\
\text { and texts change }\end{array}$ & $\begin{array}{l}\text { In the middle within } \\
\text { an odd shape }(1 / 3 \\
\text { size })\end{array}$ \\
\hline Expedia.com & White & $\begin{array}{l}\text { Yes } \\
\text { (medium) }\end{array}$ & $\begin{array}{l}\text { Yes (irrelevant)/ } \\
\text { No (random ad } \\
\text { such as } \\
\text { Yosemite Park, } \\
\text { Puerto Villarta, } \\
\text { Travel } \\
\text { protection } \\
\text { plan)/(slogan) }\end{array}$ & $\begin{array}{l}\text { Irrelevant (flight } \\
\text { information, } \\
\text { slogan in a box) }\end{array}$ & $\begin{array}{l}\text { Circles moving } \\
\text { across as the } \\
\text { progress bar }\end{array}$ & $\begin{array}{l}\text { Top and middle (1/3 } \\
\text { size) }\end{array}$ \\
\hline Orbitz.com & Blue & Yes (small) & $\begin{array}{l}\text { No (a popup ad } \\
\text { came up) }\end{array}$ & $\begin{array}{l}\text { Irrelevant } \\
\text { (slogan in a big } \\
\text { box) }\end{array}$ & $\begin{array}{l}\text { Three circles } \\
\text { moving across as } \\
\text { the progress bar }\end{array}$ & $\begin{array}{l}\text { Top and middle (1/3 } \\
\text { size) }\end{array}$ \\
\hline
\end{tabular}




\section{Table F2. Descriptions of Waiting Screens of Eleven Travel Sites (Continued)}

\begin{tabular}{|c|c|c|c|c|c|c|}
\hline Site & $\begin{array}{l}\text { Background } \\
\text { Color }\end{array}$ & Logo & Image & Text & Image Motion & Position \\
\hline Travelocity.com & $\begin{array}{l}\text { Dark Dodger } \\
\text { Blue }\end{array}$ & $\begin{array}{l}\text { Yes (small at } \\
\text { the right- } \\
\text { bottom) }\end{array}$ & $\begin{array}{l}\text { Yes (Irrelevant, } \\
\text { random ad - } \\
\text { Colorado, } \\
\text { slogan) }\end{array}$ & $\begin{array}{l}\text { Irrelevant } \\
\text { (searching, add } \\
\text { a hotel ..., Did } \\
\text { you know ...) }\end{array}$ & No & Top middle ( $1 / 3$ size $)$ \\
\hline Priceline.com & Deep Sky Blue & $\begin{array}{l}\text { Yes } \\
\text { (medium) }\end{array}$ & $\begin{array}{l}\text { Yes (dynamic, } \\
\text { irrelevant, } \\
\text { commercial } \\
\text { guy) }\end{array}$ & $\begin{array}{l}\text { Irrelevant (flight } \\
\text { information, } \\
\text { slogan, fine } \\
\text { print) }\end{array}$ & $\begin{array}{l}\text { Circles moving } \\
\text { across as the } \\
\text { progress bar }\end{array}$ & $\begin{array}{l}\text { Top and middle (1/3 } \\
\text { size) }\end{array}$ \\
\hline Tripadvisor.com & Dark Pale Green & $\begin{array}{l}\text { Yes } \\
\text { (immediate } \\
\text { regular } \\
\text { screen) }\end{array}$ & No & $\begin{array}{l}\text { Irrelevant (flight } \\
\text { information, } \\
\text { searching, etc.) }\end{array}$ & $\begin{array}{l}\text { Show some } \\
\text { results first and } \\
\text { animation on top } \\
\text { (airline logos, } \\
\text { airplanes) }\end{array}$ & Whole page \\
\hline Lowestfare.com & Dark Blue & $\begin{array}{l}\text { Yes } \\
\text { (medium) }\end{array}$ & $\begin{array}{l}\text { Yes (irrelevant, } \\
\text { an airplane } \\
\text { drawing) }\end{array}$ & $\begin{array}{l}\text { Irrelevant } \\
\text { (searching, } \\
\text { flight + hotel } \\
\text { saving, fine } \\
\text { print) }\end{array}$ & $\begin{array}{l}\text { Moving arrow } \\
\text { across circles as } \\
\text { the progress bar }\end{array}$ & Top left (1/3 size) \\
\hline
\end{tabular}




\section{Appendix G}

\section{Comparison of Best Practices, Current Practices, and Filler Interface Guidelines from Our Findings}

\begin{tabular}{|c|c|c|}
\hline $\begin{array}{l}\text { Best Practices - Recommendations } \\
\text { from Previous Literature }\end{array}$ & Current Practices - Observations & $\begin{array}{l}\text { Our Findings - Implications and } \\
\text { Guidelines }\end{array}$ \\
\hline $\begin{array}{l}\text { Provide a filler screen while users wait } \\
\text { No specific best practices found with respect to } \\
\text { providing a filler screen while users wait in the } \\
\text { online environment. - No recommendations } \\
\text { There are some best practices for managing } \\
\text { waiting time in a physical environment. } \\
\text { 1. RoninCast: Wireless Ronin Technologies - } \\
\text { Providing information on TV screens to } \\
\text { create a more relaxing and inviting } \\
\text { environment which will decrease perceived } \\
\text { wait times. } \\
\text { 2. CastOven and HappyPrinter - Using video, } \\
\text { light, and background music to entertain } \\
\text { users during waiting time and augment their } \\
\text { experience. }\end{array}$ & $\begin{array}{l}\text { No clear guideline for the use of a filler } \\
\text { screen - No uniform use of a filler screen } \\
\text { during users' wait. } \\
\text { 1. Hulu Web site and ESPN Web site - No } \\
\text { new "wait page" is displayed. They } \\
\text { present how much time is left before the } \\
\text { advertisement is over on the existing } \\
\text { page. } \\
\text { 2. Facebook - When users upload videos } \\
\text { and photos to their Facebook, they are } \\
\text { given a "status window" in a new } \\
\text { window. } \\
\text { 3. Numerous major travel Web sites - } \\
\text { Displaying a "wait page" with a variety } \\
\text { of design. } \\
\text { 4. MSDN (Microsoft Development } \\
\text { Network) - A few articles mention about } \\
\text { a simple "Please Wait ..." page. }\end{array}$ & $\begin{array}{l}\text { Our findings indicate that providing a filler } \\
\text { screen while users wait for their requested } \\
\text { results is significantly effective than not } \\
\text { displaying a filler screen with respect to } \\
\text { reducing perceived waiting time. } \\
\rightarrow \text { Web sites or user interface designers } \\
\text { should implement a filler screen } \\
\text { whenever an unavoidable wait situation } \\
\text { occurs. }\end{array}$ \\
\hline $\begin{array}{l}\text { Design a filler screen with text and/or image } \\
\text { 1. Shneiderman and Plaisant (2010), } \\
\text { Designing the User Interface: Strategies for } \\
\text { Effective Human-Computer Interaction, and } \\
\text { Apple Computer Inc. (2008), "Apple Human } \\
\text { Interface Guidelines" - Designing user inter- } \\
\text { face in general where general discussions } \\
\text { and suggestions are provided and most of } \\
\text { them are neither specific to filler screen } \\
\text { design nor specific to various element } \\
\text { designs on a filler screen. } \\
\text { 2. US Patent } 6,304,852 \text { : Method of } \\
\text { Communicating Computer Operation During } \\
\text { a Wait Period - In a method of displaying } \\
\text { advertising and communicating computer } \\
\text { operation during a wait period, a plurality of } \\
\text { images is displayed during the wait period in } \\
\text { a predetermined sequence as part of an } \\
\text { animation that indicates that the wait period } \\
\text { is proceeding. Advertising information is } \\
\text { integrated with the plurality of images. }\end{array}$ & $\begin{array}{l}\text { Almost all major travel Web sites display a } \\
\text { variation of filler screen while processing } \\
\text { users' request. These Web sites adopt } \\
\text { different content and design on their filler } \\
\text { screen; however, these filler screens on } \\
\text { the market appear to be designed largely } \\
\text { based on designers' introspection and } \\
\text { intuition, leading to irregular patterns and } \\
\text { implementation styles (e.g., images and } \\
\text { text, color, animation, etc.). } \\
\text { 1. Orbitz.com - Showing text message } \\
\text { (slogan) but no image. } \\
\text { 2. Travelocity.com - Showing text mes- } \\
\text { sage (e.g., searching, add a hotel ..., } \\
\text { Did you know ...) and a random image } \\
\text { (e.g., a place, a slogan). } \\
\text { 3. Expedia.com - Showing text message } \\
\text { (e.g., flight information, slogan in a box) } \\
\text { and a random ad image (e.g., Yosemite } \\
\text { Park, Puerto Villarta, travel protection } \\
\text { plan). } \\
\text { 4. Hotwire.com - Showing text message } \\
\text { (flight information in the shaded back- } \\
\text { ground) and a random image. }\end{array}$ & $\begin{array}{l}\text { Our findings suggest that displaying visual } \\
\text { elements (such as text or image) on a filler } \\
\text { interface works significantly better than } \\
\text { using no such design elements with respect } \\
\text { to reducing perceived waiting time. } \\
\rightarrow \text { Web sites or user interface designers } \\
\text { should consider adding basic visual cues } \\
\text { (text or image) on their filler interfaces in } \\
\text { order to manipulate customers' time } \\
\text { perceptions. }\end{array}$ \\
\hline
\end{tabular}




\begin{tabular}{|c|c|c|}
\hline $\begin{array}{l}\text { Best Practices - Recommendations } \\
\text { from Previous Literature }\end{array}$ & Current Practices - Observations & $\begin{array}{l}\text { Our Findings - Implications and } \\
\text { Guidelines }\end{array}$ \\
\hline $\begin{array}{l}\text { Design a filler screen with relevant text } \\
\text { and/or image } \\
\text { 1. US Patent 5,996,007: Method for Providing } \\
\text { Selected Content during Waiting Time of an } \\
\text { Internet Session - Selected content such as } \\
\text { product information and announcements is } \\
\text { provided during waiting time of an Internet } \\
\text { session. In one implementation, the process } \\
\text { implemented by the waiting time message } \\
\text { program of the invention involves monitoring } \\
\text { a user node to identify a web site access } \\
\text { request, accessing a previously stored mes- } \\
\text { sage set, selecting a message from the } \\
\text { message set and displaying or playing back } \\
\text { the selected message. The message set } \\
\text { and particular messages may be selected } \\
\text { based on user information (e.g., demo- } \\
\text { graphic, psychographic, or product } \\
\text { preference information), information } \\
\text { regarding the expected waiting time or other } \\
\text { information. }\end{array}$ & $\begin{array}{l}\text { Almost all major travel Web sites adopt } \\
\text { different some type of text and/or image on } \\
\text { their filler screen; however, these texts and } \\
\text { images on filler screens are not relevant to } \\
\text { users' tasks and purposes. } \\
\text { 1. cheapOair.com - Showing generic } \\
\text { (irrelevant) text message (e.g., about } \\
\text { flight database) but no image. } \\
\text { 2. CheapTickets.com - Showing generic } \\
\text { (irrelevant) text message (slogan) and } \\
\text { generic (irrelevant) image (a large circle } \\
\text { with "No Booking Fee"). } \\
\text { 3. Lowestfare.com - Showing generic } \\
\text { (irrelevant) text message (e.g., } \\
\text { searching, flight + hotel saving, fine } \\
\text { print) and generic (irrelevant) image (an } \\
\text { airplane drawing). } \\
\text { 4. CheapAir.com - Showing generic } \\
\text { (irrelevant) text message (e.g., please } \\
\text { wait, etc.) but no image. }\end{array}$ & $\begin{array}{l}\text { Our findings provide strong evidence for } \\
\text { inclusion of task-relevant information on filler } \\
\text { interfaces. Relevant visual cues (text and } \\
\text { image) were shown to be significantly more } \\
\text { effective than generic visual cues with } \\
\text { respect to reducing perceived waiting time. } \\
\rightarrow \text { Web sites or user interface designers } \\
\text { should use task-relevant visual cues (text } \\
\text { and image) whenever possible on their } \\
\text { filler interfaces to assist users' } \\
\text { tasks/purposes and usage contexts such } \\
\text { as travel destinations (e.g., for airfare } \\
\text { booking), products and services (e.g., for } \\
\text { keyword search), features and functions } \\
\text { (e.g., for software installation), special } \\
\text { offers and promotions (e.g., for music } \\
\text { download), and other wait situations. }\end{array}$ \\
\hline $\begin{array}{l}\text { Design a filler screen with multiple and } \\
\text { dynamically changing images } \\
\text { No specific best practices found with respect to } \\
\text { providing moving images on a filler screen } \\
\text { while users wait in the online environment - No } \\
\text { recommendations. } \\
\text { There are some best practices for managing } \\
\text { waiting time with busy indicators and system } \\
\text { feedback. } \\
\text { 1. SAP Design Guide: Waiting at the Com- } \\
\text { puter: Busy Indicators and System } \\
\text { Feedback - Discuss how to use busy } \\
\text { indicator, working indicator, system mes- } \\
\text { sages, progress indicator, static wait } \\
\text { cursors, animated cursors, and wait } \\
\text { animations at three different wait situations } \\
\text { (levels, lengths) - perceptual, dialog, and } \\
\text { cognitive. }\end{array}$ & $\begin{array}{l}\text { No clear guideline for the use of multiple } \\
\text { and dynamically changing images on a } \\
\text { filler screen - No uniform use. } \\
\text { 1. Netscape - A macro will perform a Wait } \\
\text { for Web Page in Netscape } 7.1 \text { by } \\
\text { watching an area on the browser's } \\
\text { window that changes color when a Web } \\
\text { page is loading and then wait for that } \\
\text { color to return to normal. } \\
\text { 2. Priceline.com - Showing texts (e.g., } \\
\text { flight information, slogan, fine print) and } \\
\text { dynamic images (e.g., a series of } \\
\text { images of Priceline "commercial guy"). }\end{array}$ & $\begin{array}{l}\text { Our findings suggest that showing moving } \\
\text { images on a filler interface is significantly } \\
\text { better than using only a static image with } \\
\text { respect to reducing perceived waiting time. } \\
\rightarrow \text { Web sites or user interface designers } \\
\text { should display multiple and dynamically } \\
\text { changing images instead of just one } \\
\text { static image. }\end{array}$ \\
\hline
\end{tabular}

\section{References}

Apple Computer, Inc. 2008. “Apple Human Interface Guidelines,” Cupertino, CA (http://developer.apple.com/mac/library/documentation/ userexperience/conceptual/applehiguidelines/ XHIGIntro/XHIGIntro.html; accessed June 9, 2008).

Shneiderman, B., and Plaisant, C. 2010. Designing the User Interface: Strategies for Effective Human-Computer Interaction ( $5^{\text {th }}$ ed.), Boston, MA: Addison-Wesley. 
Copyright of MIS Quarterly is the property of MIS Quarterly \& The Society for Information Management and its content may not be copied or emailed to multiple sites or posted to a listserv without the copyright holder's express written permission. However, users may print, download, or email articles for individual use. 